\title{
Pseudomonas syringae pv. phaseolicola Mutants Compromised for Type III Secretion System Gene Induction
}

\author{
Xin Deng, ${ }^{1}$ Yanmei Xiao, ${ }^{1}$ Lefu Lan, ${ }^{1}$ Jian-Min Zhou, ${ }^{2}$ and Xiaoyan Tang ${ }^{1}$ \\ ${ }^{1}$ Department of Plant Pathology, Kansas State University, Manhattan, KS 66506-5502; ${ }^{2}$ National Institute of Biological Science, \\ Beijing, China
}

Submitted 14 January 2009. Accepted 12 April 2009.

Pseudomonas syringae bacteria utilize the type III secretion system (T3SS) to deliver effector proteins into host cells. The T3SS and T3 effector genes (together called the T3 genes hereafter) are repressed in nutrient-rich medium but rapidly induced after the bacteria are transferred into minimal medium or infiltrated into plants. The induction of the T3 genes is mediated by HrpL, an alternative sigma factor that recognizes the conserved hrp box motif in the T3 gene promoters. The induction of $h r p L$ is mediated by HrpR and HrpS, two homologous proteins that bind the hrpL promoter. To identify additional genes involved in regulation of the $\mathrm{T} 3$ genes, we screened for the $P$. syringae pv. phaseolicola NPS3121 transposon-tagged mutants with reduced induction of avrPto-luc and hrpL-luc, reporter genes for promoters of effector gene avrPto and $h r p L$, respectively. Determination of the transposon-insertion sites revealed genes with putative functions in signal transduction and transcriptional regulation, protein synthesis, and basic metabolism. A transcriptional regulator (AefR NPS3121) was identified in our screen that is homologous to AefR of $P$. syringae pv. syringae strain $B 728 \mathrm{a}$, a regulator of the quorum-sensing signal and epiphytic traits, but was not known to regulate the T3 genes. AefR $\mathrm{NPS}_{\mathrm{N} 121}$ in $P$. syringae pv. phaseolicola NPS3121 and AefR in $P$. syringae pv. syringae $\mathrm{B} 728$ a behave similarly in regulating the quorumsensing signal in liquid medium but differ in regulating the epiphytic traits, including swarming motility, leaf entry, and epiphytic survival.

Like many pathogenic proteobacteria, pathovars of Pseudomonas syringae rely on the type III secretion system (T3SS) for parasitism (Jin et al. 2003). The T3SS is encoded by the hypersensitive response and pathogenicity $(\mathrm{hrp} / \mathrm{hrc})$ genes that are essential for disease development on host plants and hypersensitive response (HR) on resistant plants and nonhost plants (Collmer et al. 2000). Through the TTSS, bacteria inject an array of virulence proteins termed T3 effectors into the host cells (Galan and Collmer 1999). A number of T3 effectors have been shown to suppress the host basal defense systems (Zhou and Cai 2008). In resistant plants, however, the effectors are recognized by the plant disease resistance proteins, which

Corresponding author: Xiaoyan Tang; Telephone: +1.785 .532 .1345 ; Fax: +1.785.532.5692; E-mail: xtang@ksu.edu

*The $\boldsymbol{e}$-Xtra logo stands for "electronic extra" and indicates that three figures are published online. trigger the HR and disease resistance (Alfano and Collmer 2004).

The T3SS and T3 effector genes (together called the T3 genes hereafter) of $P$. syringae bacteria are repressed in nutrient-rich medium such as King's B (KB) (King et al. 1954) but are induced in minimal medium (MM) and in the plant (Tang et al. 2006). The induction of the T3 genes is mediated by HrpL, an alternate sigma factor that recognizes the conserved hrp box motif in the promoter of T3 genes (Ferreira et al. 2006; Fouts et al. 2002; Lan et al. 2006; Xiao and Hutcheson 1994). The $h r p L$ gene itself is induced under the same conditions (Thwaites et al. 2004). hrpL induction is mediated by HrpR and HrpS, two DNA-binding proteins that form a heterodimer on the $h r p L$ promoter (Hutcheson et al. 2001; Xiao et al. 1994). The HrpR/HrpS heterodimer activates hrpL transcription by interacting with the alternate sigma factor RpoN (Chatterjee et al. 2003; Hendrickson et al. 2000). Deletion of either $h r p R$ or $h r p S$ abolishes $h r p L$ induction and bacterial pathogenicity (Xiao et al. 1994). Additional regulators required for maximal $h r p L$ induction include CorR, which also regulates coronatine synthesis, and PsrA, which regulates production of the quorum-sensing signal $N$-acyl homoserine lactones (AHL). CorR regulates $h r p L$ by binding directly to the $h r p L$ promoter (Sreedharan et al. 2006). PsrA directly binds the $r p o S$ promoter and aefR operator to positively regulate rpoS and negatively regulate $a e f R$, respectively (Chatterjee et al. 2007). The regulation of hrpL by PsrA is likely to be indirect (Chatterjee et al. 2007). Mutation of either corR or psrA reduces bacterial virulence but does not eliminate pathogenicity altogether (Chatterjee et al. 2007; Sreedharan et al. 2006).

HrpR and HrpS are encoded by the hrpRS operon that is moderately expressed in KB medium and further induced twoto fourfold in MM and in the plant (Grimm et al. 1995; Hutcheson et al. 2001; Rahme et al. 1992; Thwaites et al. 2004). The hrpRS operon is regulated by two loci encoding the two-component systems GacS/GacA and RhpS/RhpR (Chatterjee et al. 2003; Xiao et al. 2007). GacS is a sensor histidine kinase whereas $\mathrm{GacA}$ is the cognate response regulator of GacS. In $P$. syringae pv. tomato strain DC3000, gac $A^{-}$mutation significantly attenuates the transcription of hrpRS, rpoN, and $h r p L$ (Chatterjee et al. 2003). GacS is hypothesized to be activated by an as-yet-unidentified signal, which in turn phosphorylates GacA, and the phosphorylated GacA then induces, either directly or indirectly, the $h r p R S$ operon (Chatterjee et al. 2003). The role of $\mathrm{RhpS} / \mathrm{RhpR}$ in regulating the $h r p R S$ operon is indicated by mutation of the sensor kinase gene $\operatorname{rhpS}$, which abolishes hrpRS induction in the plant and in MM (Xiao et al. 2007). However, disruption of the cognate response regulator 
gene $\operatorname{rhpR}$ in the $r h p S^{-}$mutant or deletion of the $\operatorname{rhpRS}$ locus completely restores the $h r p R S$ induction, suggesting that RhpR is a negative regulator of $h r p R S$. In addition to $\mathrm{GacS} / \mathrm{GacA}$ and RhpS/RhpR, the hrpA gene encoding T3 pilin was also found to affect hrpRS induction through an unknown mechanism. Transcription of the $h r p R S$ operon, $h r p L$, and T3 genes is severely reduced in the $h r p A^{-}$mutant (Wei et al. 2000).

Another level of control of T3 gene induction involves the stability of HrpR protein, which is regulated by ATP-dependent protease Lon (Bretz et al. 2002). HrpR is stabilized in a lon ${ }^{-}$mutant, leading to elevated expression of $h r p L$ and T3 genes in KB medium (Bretz et al. 2002; Lan et al. 2007). The impact of the $l o n^{-}$mutation on $h r p L$ expression exhibits a dynamic change in MM. hrpL is expressed at a higher level in the lon ${ }^{-}$mutant than in the wild-type (WT) strain shortly after induction in MM, but is more abundant in the WT strain at later time points (Lan et al. 2007). HrpS protein stability is not affected by the lon $^{-}$mutation. However, HrpS activity is repressed by $\mathrm{HrpV}$, another negative regulator of the T3 genes that physically interacts with HrpS (Preston et al. 1998; Wei et al. 2005). HrpV-mediated repression can be cleared by HrpG, a protein that interacts with $\mathrm{HrpV}$ and liberates $\mathrm{HrpS}$ from the HrpV repression (Wei et al. 2005).

The induction of the T3 genes in MM provides an assay system for genetic identification of regulators of the T3 genes. Hendrickson and associates (2000) conducted a screen for $P$. syringae pv. maculicola ES4326 mutants that compromised the induction of the T3 genes in MM. From a total of 14,000 colonies, 297 mutants were identified. However, none of these mutant genes was cloned.

To identify additional regulators of the T3 genes, $P$. syringae pv. phaseolicola NPS3121 transposon-tagged mutants were screened on the basis of their weak induction of avrPto-luc and $h r p L-l u c$ reporter genes in MM. avrPto is a T3 effector gene of $P$. syringae pv. tomato DC3000 that carries a typical hrp box promoter (Salmeron and Staskawicz 1993). avrPtoluc in P. syringae pv. phaseolicola NPS3121 is induced in MM and in the plant in an $h r p L$ - and $h r p R S$-dependent manner (Xiao et al. 2004; Xiao et al. 2007). Here, we report the mutant genes identified in our screen.

\section{RESULTS}

\section{Isolation of $P$. syringae pv. phaseolicola mutants} using the avrPto-luc reporter.

P. syringae pv. phaseolicola NPS3121 carrying the avrPto$l u c$ reporter displayed low luciferase (LUC) activity in KB medium but high LUC activity in MM. This strain was subjected to $\mathrm{EZ}: \mathrm{TN}<\mathrm{Kan}-2>$ transposon insertion mutagenesis. In total, 11,872 mutant clones were screened for reduced LUC activity $6 \mathrm{~h}$ after induction in MM. Clones that displayed a LUC activity $<20 \%$ of the parental strain were selected and named MM-insensitive ( $\mathrm{min}$ ) mutants. In all, 84 mutants were recovered from the screening (Table 1; Supplementary Fig. S1).

Transposon insertion sites in these mutants were determined by two-stage semidegenerated polymerase chain reaction (PCR) (Jacobs et al. 2003), and the flanking sequences were searched against the $P$. syringae pv. phaseolicola 1448A genomic sequence (Joardar et al. 2005). These mutants were distributed among 45 loci, which can be divided into four groups based on the putative gene function (Table 1). Genes in group A encode proteins with a role in signal perception and transduction, including $h r p S$, rhpS, and PSPPH_3244 ${ }_{N P S 3121}$. hrpS and rhpS are known regulators of the T3 genes (Xiao et al. 1994, 2007). PSPPH_3244 ${ }_{N P S 3121}$ encodes a transcriptional regulator with $87 \%$ amino acid sequence identity to AefR, a regulator of quorum-sensing signal and epiphytic fitness in $P$. syringae pv. syrin- gae B728a strain (Quinones et al. 2004, 2005). Mutants of hrpL, $h r p R$, and other known regulatory genes were not identified in the screening. Group B has two genes encoding putative membrane proteins. $P S P P H \_4907_{N P S 3121}$ encodes a porin protein in the OprD family that functions in trafficking small molecules across the outer membrane (Hancock and Brinkman 2002). PSPPH_5137 ${ }_{N P S 3121}$ encodes a putative integral membrane protein of the YeeE/YedE family with an unknown function (Joardar et al. 2005). Group C has only one gene, trmE, which encodes a tRNA modification GTPase (Joardar et al. 2005). Mutation of trmE increases the rate of misincorporation of amino acids and frame-shifting during the translation process (Cabedo et al. 1999). Mutation of this gene in Shigella flexneri reduces bacterial virulence (Durand et al. 1997). Most of the mutant genes belong to group D that encode functions in basic metabolism. Twelve genes are involved in porphyrin metabolism (Table 1). Nineteen genes are involved in the biosynthesis of amino acids arginine, glutamine, glutamic acid, histidine, valine, isoleucine, leucine, methionine, serine, and tryptophan (Table 1). The induction of LUC activity in the amino acid biosynthesis mutants was restored by adding corresponding amino acids to $0.1 \mathrm{mM}$ in the MM. Three genes are in an operon required for fructose uptake and metabolism (Joardar et al. 2005). Two genes encode enzymes that function in purine synthesis. Four additional metabolic genes are eno- 1 , encoding enolase; $P S P P H_{-}$ $2878_{N P S 3121}$, encoding a glycosyl hydrolase; sypA, encoding a putative peptide/siderophore synthase, and PSPPH_0569 ${ }_{\text {NPS3121 }}$, encoding a putative ATP phosphoribosyltransferase subunit.

All the mutants were examined for growth in MM. Mutants in groups $\mathrm{A}, \mathrm{B}$, and $\mathrm{C}$ displayed approximately seven- to ninefold multiplication $36 \mathrm{~h}$ after culture in MM, which was similar to the WT strain. However, mutants in group D showed little growth in MM.

\section{Mutant screening using the hrpL-luc reporter.}

The use of avrPto-luc as reporter led to the identification of a large number of metabolic mutants and only three genes with regulatory functions. Many genes with a known function in regulating the $\mathrm{T} 3$ genes were not identified in the screening. Because the screening was approximately $2 \times$ coverage of the $P$. syringae pv. phaseolicola genome, we decided to screen more mutants using hrpL-luc as reporter. To avoid metabolic mutants, mutants with low hrpL-luc reporter activity were assayed for growth in MM, and those with growth defect were discarded.

Eight mutants were obtained from a total of 16,000 clones. Five mutations were in the $r h p S$ gene, one in $P S P P H_{-}$ $3244_{N P S 3121}$, one in trmE, and one in miaA (Table 1). Mutants of rhpS, PSPPH_3244 ${ }_{N P S 3121}$, and trmE genes were obtained in the screening with avrPto-luc reporter. miaA encodes tRNA isopentenyltransferase and, like trmE, also has a function in protein translation (Leung et al. 1997). Except for $r h p S$ and PSPPH_3244 ${ }_{N P S 3121}$, no gene with a regulatory function was identified in this screening.

\section{Evaluation of the reporter genes.}

It was puzzling that a large number of metabolic mutants and only a few regulatory mutants were recovered from the mutant screening. One possibility was that the metabolic mutants were lethal in MM, as indicated by the lack of bacterial growth in MM. Therefore, we decided to evaluate the reporter genes with the mutant strains to determine whether the reporter gene activities were consistent with the levels of $h r p L$ RNA.

We first analyzed the levels of $h r p L$ RNA in representative mutants of each functional group that were isolated based on the avrPto-luc reporter activity (Fig. 1A). All mutants except min93 exhibited good correlation between the avrPto-luc re- 
porter activity and the level of $h r p L$ RNA (Fig. 1A). The min93 mutant had normal induction of $h r p L$ RNA but the LUC activity was almost undetectable in this mutant.

We then tested if the hrpL-luc reporter activity was consistent with the level of $h r p L$ RNA. min 93 and six other mutants $(\min 24, \min 4, \min 32, \min 42, \min 49$, and $\min 62)$ were cured of the avrPto-luc reporter plasmid, the hrpL-luc reporter plasmid was introduced into each, and LUC activity derived from hrpL-luc was measured (Fig. 1B). The hrpL-luc reporter activ- ity was almost undetectable in the $\min 93$ mutant but the $h r p L$ $l u c$ reporter activities in other mutants generally agreed with the levels of hrpL RNA.

We further conducted a Western blot analysis of the LUC protein derived from hrpL-luc in min93 and other mutants (Fig. 1C). A high level of LUC protein was detected in the min93 mutant, suggesting that this mutation impaired the detection of LUC enzymatic activity rather than the induction of the T3 genes. The levels of LUC protein in other mutants were

Table 1. Minimal medium-insensitive ( $\min )$ mutants $^{\mathrm{a}}$

\begin{tabular}{|c|c|c|c|c|}
\hline Genes $^{\text {b }}$ & Mutants & Gene products & Pathways of biological processes & $\begin{array}{l}\text { Disease } \\
\text { index }\end{array}$ \\
\hline \multicolumn{5}{|l|}{ Group A } \\
\hline $\operatorname{rhpS}$ & $\begin{array}{l}\min 12,80, L 1, L 2, L 3 \\
\quad L 5, L 7\end{array}$ & Sensor histidine kinase & Sional transduction & 0 \\
\hline hrpS & $\min 08,94,96$ & Type III transcriptional regulator & Signal transduction & 0 \\
\hline aefR & $\min 16, L 4$ & Transcriptional regulator & Signal transduction & 2 \\
\hline \multicolumn{5}{|l|}{ Group B } \\
\hline PSPPH_4907 & $\min 79,93$ & Outer membrane porin & Membrane protein & 2 \\
\hline PSPPH_5137 & $\min 107$ & YeeE/YedE family protein & Putative membrane protein & 1 \\
\hline \multicolumn{5}{|c|}{ Group $\mathrm{C}^{-}$} \\
\hline $\operatorname{trmE}$ & $\min 47, L 8$ & tRNA modification GTPase & Translation & ND \\
\hline $\operatorname{miaA}$ & $\min L 6$ & tRNA modification isopentenyltransferase & Translation & 1 \\
\hline \multicolumn{5}{|c|}{ ela } \\
\hline cbiD & $\min 83$ & Cobalamin biosynthesis protein & Porphyrin and chlorophyll metabolism & 1 \\
\hline cbiG & $\min 75$ & Precorrin-3B C17-methyltransferase & Porphyrin and chlorophyll metabolism & 2 \\
\hline $\operatorname{cobC}$ & $\min 87$ & Cobalamin biosynthesis protein & Porphyrin and chlorophyll metabolism & 1 \\
\hline $\mathrm{cobH}$ & $\min 103$ & Precorrin-8X methylmutase & Porphyrin and chlorophyll metabolism & 1 \\
\hline $\operatorname{cobM}$ & $\min 30,50,55,56$ & Precorrin-4 C11-methyltransferase & Porphyrin and chlorophyll metabolism & 1 \\
\hline $\operatorname{cobN}$ & $\min 66,69$ & CobN/magnesium chelatase family protein & Porphyrin and chlorophyll metabolism & 1.5 \\
\hline $\operatorname{cob} Q$ & $\min 51$ & Cobyric acid synthase & Porphyrin and chlorophyll metabolism & 1 \\
\hline PSPPH_3701 & $\min 104,106$ & Cobyrinic acid a,c-diamide synthase & Porphyrin and chlorophyll metabolism & NA \\
\hline PSPPH_2598 & $\min 64,95$ & Tetrapyrrole methylase family protein & Porphyrin and chlorophyll metabolism & 2 \\
\hline PSPPH_2227 & $\min 77$ & Magnesium chelatase subunit ChlD & Porphyrin and chlorophyll metabolism & 1 \\
\hline bchI & $\min 29,54$ & Magnesium chelatase, subunit Chil, putative & Porphyrin and chlorophyll metabolism & 1.5 \\
\hline \multirow{3}{*}{$\begin{array}{l}\arg H \\
\text { gltB }\end{array}$} & $\min 10,13,45,68$ & Argininosuccinate lyase & Arginine biosynthesis & 1.5 \\
\hline & $\min 04,15,20,25,26,33$, & & & \\
\hline & $40,43,52,67,99$ & Glutamate synthase, large subunit & Glutamate biosynthesis & 1.7 \\
\hline gltD & $\min 22,28$ & Glutamate synthase, small subunit & Glutamate biosynthesis & 2.5 \\
\hline hisA & $\min 38$ & $\begin{array}{l}\text { Phosphoribosylformimino-5-aminoimidazole } \\
\text { carboxamide ribotide isomerase }\end{array}$ & Histidine biosynthesis & 1 \\
\hline hisB & $\min 59,74$ & Imidazoleglycerol-phosphate dehydratase & Histidine biosynthesis & 2.5 \\
\hline hisC & $\min 05,11$ & Histidinol-phosphate aminotransferase & Histidine biosynthesis & 2 \\
\hline hisD & $\min 37,76$ & Histidinol dehydrogenase & Histidine biosynthesis & 1.5 \\
\hline hisE & $\min 53$ & Phosphoribosyl-ATP pyrophosphatase & Histidine biosynthesis & 3 \\
\hline hisF & $\min 24,34$ & Imidazoleglycerol phosphate synthase, cyclase & Histidine biosynthesis & 0.5 \\
\hline hisH & $\min 35,36$ & Amidotransferase & Histidine biosynthesis & 0 \\
\hline$i l v D$ & $\min 32,86$ & Dihydroxy-acid dehydratase & Valine and isoleucine biosynthesis & 0 \\
\hline $\operatorname{leu} A$ & $\min 09,14,82$ & 2-Isopropylmalate synthase & Leucine biosynthesis & 0.3 \\
\hline leuB & $\min 21,39,61$ & 3-Isopropylmalate dehydrogenase & Leucine biosynthesis & 0 \\
\hline leuC & $\min 60$ & 3-Isopropylmalate dehydratase, large subunit & Leucine biosynthesis & 0 \\
\hline metF & $\min 49,84$ & 5,10-Methylenetetrahydrofolate reductase & Methionine biosynthesis & 1.5 \\
\hline metH & $\min 92,108$ & 5-Methyltetrahydrofolate homocysteine methyltransferase & Methionine biosynthesis & 1.5 \\
\hline $\operatorname{ser} A$ & $\min 42,73$ & D-3-phosphoglycerate dehydrogenase & L-serine biosynthesis & 1 \\
\hline $\operatorname{trp} A$ & $\min 62$ & Tryptophan synthase, alpha subunit & Tryptophan biosynthesis & 0 \\
\hline $\operatorname{trpD}$ & $\min 71$ & Anthranilate phosphoribosyl transferase & Tryptophan biosynthesis & 0 \\
\hline \multirow[t]{2}{*}{ PSPPH_0847 } & $\min 65,98$ & Phosphoenolpyruvate-protein & & \\
\hline & & phosphotransferase,EI/HPr/EIIA components & Fructose and mannose metabolism & 2 \\
\hline fruK & $\min 18$ & 1-Phosphofructokinase & Fructose and mannose metabolism & 2 \\
\hline PSPPH_0849 & $\min 41$ & $\begin{array}{l}\text { Phosphotransferase system, fructose-specific IIBC } \\
\text { component }\end{array}$ & Fructose and mannose metabolism & 2 \\
\hline purE & $\min 78$ & $\begin{array}{l}\text { Phosphoribosylaminoimidazole carboxylase, catalytic } \\
\text { subunit }\end{array}$ & Purine metabolism & 2 \\
\hline purK & $\min 27$ & $\begin{array}{l}\text { Phosphoribosylaminoimidazole carboxylase, atpase } \\
\text { subunit }\end{array}$ & Purine metabolism & 0 \\
\hline eno-1 & $\min 23$ & Enolase & Glycolysis; gluconeogenesis & 1 \\
\hline PSPPH_2878 & $\min 85$ & Glycosyl hydrolase, family 15 & Polysaccharide metabolism & 1 \\
\hline sypA & $\min 63$ & Putative peptide/siderophore synthetase & $\ldots$ & 3 \\
\hline PSPPH_0569 & $\min 02$ & ATP phosphoribosyltransferase subunit, putative & $\ldots$ & 2 \\
\hline
\end{tabular}

a Mutants isolated with the avrPto-luc reporter are indicated by min followed by a number. Mutants isolated with the $h r p L-l u c$ reporter are indicated by min followed by $L$ and a number. Genes with transposon insertions are named according to their homologs in the Pseudomonas syringae pv. phaseolicola 1448A strain. $\mathrm{ND}=$ not determined.

${ }^{\mathrm{b}}$ Group A: signal sensor or transcriptional regulator, group B: membrane proteins, group C: protein translation, and group D: metabolic genes. 
generally consistent with the hrpL-luc reporter activities and the levels of $h r p L$ RNA. These results indicated that the activities of avrPto-luc and hrpL-luc reporter genes generally reflected the level of $h r p L$ RNA expression in the mutant bacteria.

\section{Pathogenicity and HR assays of min mutants.}

Although numerous metabolic mutations severely compromised the induction of T3 genes in MM, many were not reported in previous studies of $P$. syringae mutants that abolished the pathogenicity or HR-inducing activity. To determine whether there is a correlation between the T3 gene expression in $\mathrm{MM}$ and pathogenicity in host plants, all the mutant strains at $2 \times 10^{4} \mathrm{CFU} / \mathrm{ml}$ were infiltrated into the primary leaves of bean plants. The degree of disease symptoms was evaluated according to a disease index (Supplementary Fig. S2). The WT strain caused the most concentrated specks and was assigned a disease index of 3 . The $h r p S$ mutants were symptom-free and assigned an index of 0 . Mutants with the disease symptoms in between were assigned an index of 1 or 2 . A number of metabolic mutants, including $\min 24, \min 35$, and $\min 36$ for histidine synthesis, $\min 9, \min 14, \min 21, \min 39, \min 61$, and $\min 60$ for leucine synthesis, $\min 32$ and $\min 86$ for valine and isoleucine synthesis, min62 and $\min 71$ for tryptophan synthesis, and $\min 27$ for purine synthesis, failed to elicit any visible disease symptoms. Mutants with defects in histidine, leucine, valine, isoleucine, tryptophan, and purine biosynthesis were also identified by Brooks and associates (2004) in a screening of $P$. syringae pv. tomato DC3000 mutants that compromised the pathogenicity in Arabidopsis plants.

Representative mutants that did not elicit visible symptoms were assayed for bacterial growth 6 days after inoculation into bean plants (Fig. 2). All these mutants displayed a significant

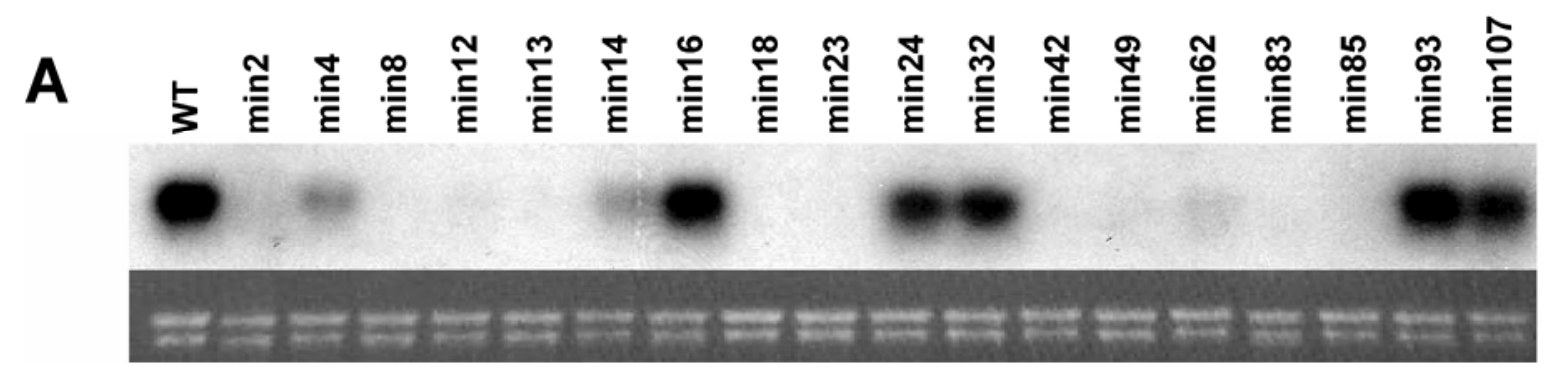

B
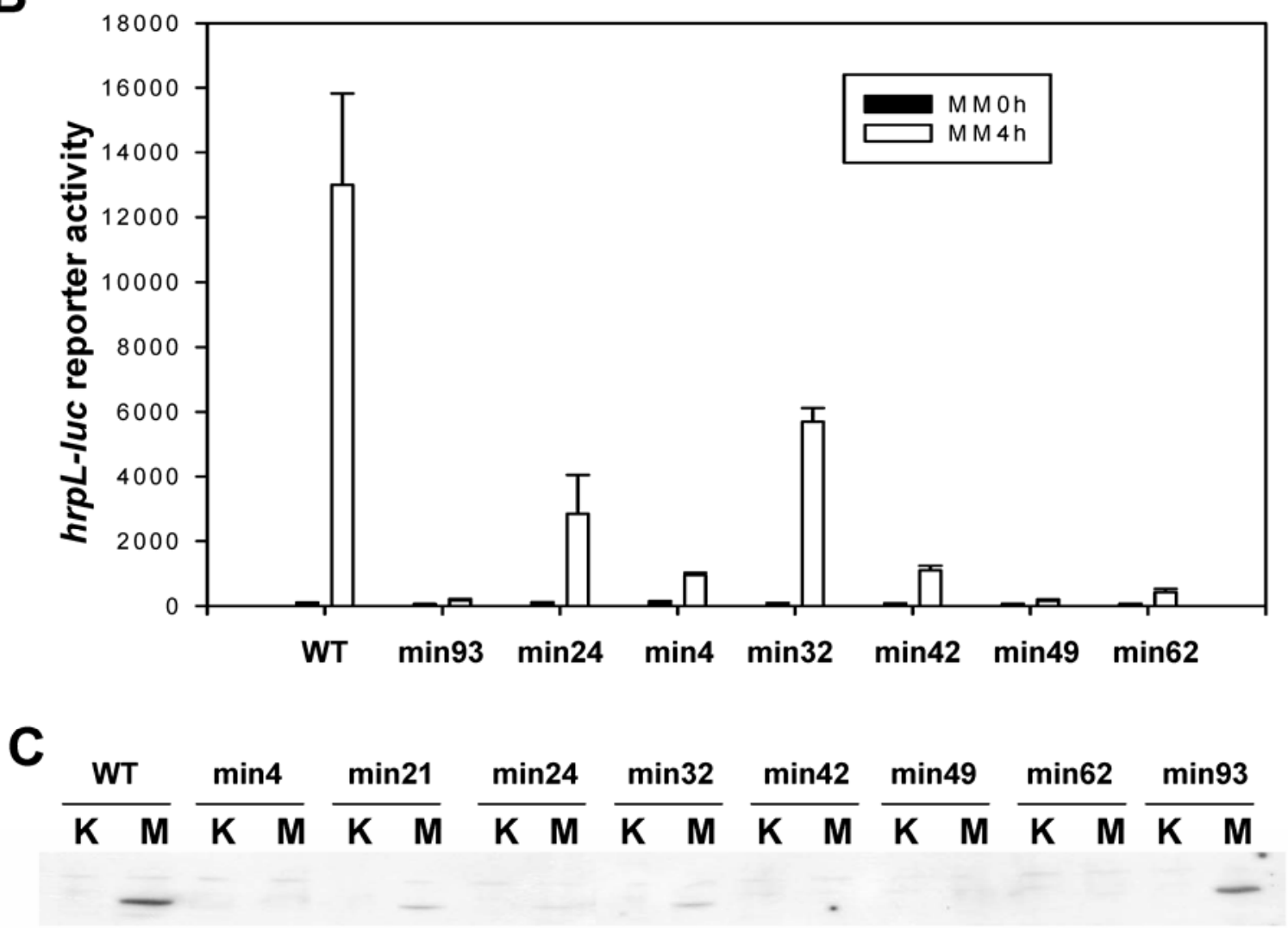

Fig. 1. Assessment of $h r p L$ RNA, $h r p L-l u c$ reporter activity, and HrpL protein in representative minimal medium-insensitive (min) mutants. A, $h r p L$ RNA. Wild-type (WT) Pseudomonas syringae pv. phaseolicola NPS3121 and min mutants were grown in King's B (KB) medium and induced in minimal medium $(\mathrm{MM})$ for $4 \mathrm{~h}$. Total RNA $(10 \mu \mathrm{g})$ from each sample was subjected to electrophoresis in a denaturing agarose gel. The blot was hybridized with DNA probes derived from the $h r p L$ coding region. Loading of RNA samples is indicated by rRNA. B, Luciferase (LUC) activity derived from $h r p L-l u c$ reporter. Bacteria were grown in $\mathrm{KB}$ medium and induced in MM for $4 \mathrm{~h}$. LUC activity was measured with a cooled charge-couple device. Each data point represents three replicates. Error bars indicate standard error. C, LUC protein derived from $h r p L$-luc reporter. The WT and min mutant strains carrying $h r p L-l u c$ reporter were grown in $\mathrm{KB}$ and induced in MM for $4 \mathrm{~h}$. Bacteria were harvested by centrifugation and resuspended in MM to an optical density at $600 \mathrm{~nm}$ of 1 . Bacteria $(30 \mu \mathrm{l})$ was boiled in $1 \times$ sodium dodecyl sulfate (SDS) sample buffer and loaded to an SDS polyacrylamide gel electrophoresis gel. Western blot was performed using anti-LUC antibodies. 
reduction of bacterial growth in the host plants, lower than that of the $r h p S^{-}$mutant $(\min 12)$. With the exception of $\min 24$ $\left(h i s F^{-}\right)$, the growth of the remaining metabolic mutants was even lower than that of the $h r p S$ mutant (min8). Although $\min 32\left(i l v D^{-}\right)$displayed a significant level of $h r p L$ RNA in MM (Fig. 1A), the growth of this mutant in host bean plants was even lower that of the $h r p S^{-}$mutant (Fig. 2). In contrast, many metabolic mutants with completely abolished $h r p L$ expression in $\mathrm{MM}$ were only slightly reduced in pathogenicity (Fig. 1A; Table 1).

Representative mutants of each functional group were also assayed for the HR-inducing activity on tobacco W38 plants (Table 2). A number of mutants that elicited significant disease symptoms on bean plants, such as $\min 4\left(\mathrm{glt} B^{-}\right)$, $\min 18\left(\right.$ fruK $\left.^{-}\right), \min 42\left(\operatorname{ser}^{-}\right), \min 49\left(\operatorname{met}^{-}\right), \min 83\left(\mathrm{cibD}^{-}\right)$, min85(Psph_2818 $\left.{ }_{N P S 3121^{-}}\right), \quad \min 93\left(P s p h \_4907_{N P S 312 I^{-}}\right), \quad$ and $\min 47\left(\mathrm{rrmE}^{-}\right)$, also elicited normal HR. On the other hand, mutants such as $\min 12\left(r h p S^{-}\right), \min 24\left(h i s F^{-}\right), \min 27\left(p u r K^{-}\right)$, $\min 32\left(i l v D^{-}\right), \min 62\left(\operatorname{trp} A^{-}\right)$, and $\min 71\left(\operatorname{trp} D^{-}\right)$that were significantly reduced in pathogenicity elicited a delayed $\mathrm{HR}$ or failed to induce a HR. However, $\min 14\left(\operatorname{leu} A^{-}\right)$and $\min 21\left(\operatorname{leu} B^{-}\right)$ mutants, although significantly reduced in pathogenicity on the host bean plants, elicited normal HR, as did the WT strain on tobacco W38 plants.

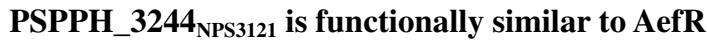

in regulating the $a h l I$ gene promoter and its own promoter.

PSPPH_3244 NPS $3121_{12}$ is $87 \%$ identical to AefR that is known to regulate the synthesis of quorum-sensing signal AHL in $P$. syringae pv. syringae B728a (Quinones et al. 2004). AefR positively regulates the ahlI gene encoding AHL synthase and autoinhibits its own promoter (Quinones et al. 2004). To determine whether PSPPH_3244 ${ }_{\mathrm{NPS} 3121}$ is functionally similar to AefR, we generated a deletion mutant of PSPPH_3244 ${ }_{N P S 3121}$ by marker exchange and examined how PSPPH_3244 ${ }_{\mathrm{NPS} 3121}$ regulates the ahlI gene promoter and its own promoter. As observed in P. syringae pv. syringae $\mathrm{B} 728 \mathrm{a}$, ahlI-luc exhibited approximately $20 \%$ expression in the $\triangle P S P P H_{-} 3244_{N P S 3121}$ mutant relative to the WT strain (Fig. 3A), and overexpression of PSPPH_3244 ${ }_{N P S 3121}$ using the pNm promoter in pML122 plasmid (Labes et al. 1990) in the deletion mutant severely inhibited the PSPPH_3244 ${ }_{N P S 3121}$ promoter, as indicated by the

Table 2. Hypersensitive response (HR) assay of representative minimal medium-insensitive ( min $)$ mutants $^{\mathrm{a}}$

\begin{tabular}{lccc}
\hline & \multicolumn{3}{c}{ Time (h) } \\
\cline { 2 - 4 } Strains & $\mathbf{1 2}$ & $\mathbf{1 4}$ & $\mathbf{1 8}$ \\
\hline WT & + & + & + \\
min4 gltB & + & + & + \\
min8 hrpS & - & - & - \\
min12 rhpS & - & + & + \\
min14 leuA & + & + & + \\
min16 aefR & + & + & + \\
min18 fruK & + & + & + \\
min21 leuB & + & + & + \\
min23 eno-1 & - & + & + \\
min24 hisF & - & + & + \\
min27 purK & - & - & - \\
min32 ilvD & - & + & + \\
min42 serA & + & + & + \\
min47 trmE & + & + & + \\
min62 trpA & - & - & - \\
min71 trpD & - & - & - \\
min83 cibD & + & + & + \\
min85 PSPPH_0569 & + & + & + \\
min93 PSPPH_4907 & + & + & + \\
min107 PPSPPH_5137 & - & + & + \\
\hline
\end{tabular}

${ }^{a}$ Wild-type (WT) strain and $\min$ mutants at $10^{8} \mathrm{CFU} / \mathrm{ml}$ were injected into the tobacco W38 leaves. The induction of nonhost HR was documented at 12,14 , and $18 \mathrm{~h}$ after inoculation; + indicates positive HR and - indicates lack of HR.

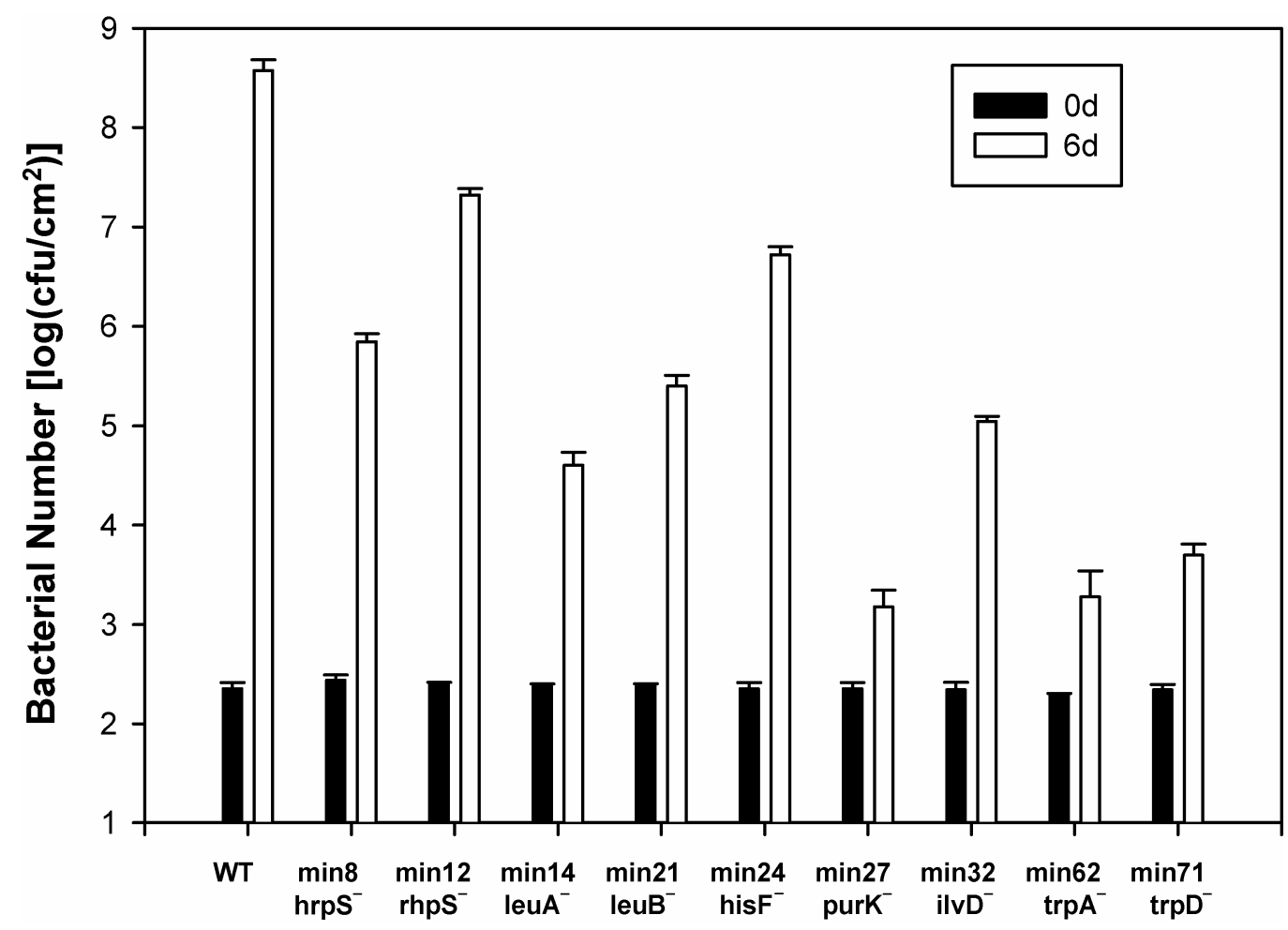

Fig. 2. Growth of minimal medium-insensitive ( $\mathrm{min}$ ) mutants in bean plants. Wild-type (WT) Pseudomonas syringae pv. phaseolicola NPS3121 and min mutants that did not elicit visible disease symptoms were inoculated into the primary bean leaves at $2 \times 10^{4} \mathrm{CFU} / \mathrm{ml}$. For each data point, three leaf disks (1 $\mathrm{cm}^{2}$ ) were removed at 0 and 6 days after inoculation and ground separately in sterile water for bacterial count. Error bars represent standard error. The experiment was repeated two times with similar results. 
low LUC activity (Fig. 3B). These results suggested that PSPPH_3244 ${ }_{\mathrm{NPS} 3121}$ is functionally similar to AefR of $P$. syringae pv. syringae $\mathrm{B} 728 \mathrm{a}$ in regulating the $\mathrm{AHL}$ signal and, hereafter, is named AefR $\mathrm{NPS}_{121}$.

Regulation of the T3 genes by AefR NPS3121 .

We used the $\triangle a e f R_{N P S 3121}$ mutant to investigate whether AefR $_{\text {NPS3121 }}$ regulates the T3 genes. Consistent with the reduced avrPto-luc and hrpL-luc activities in insertion mutants, $h r p L$ RNA was significantly reduced in the $\Delta a e f R_{N P S 312 I}$ mutant, and this was largely complemented by expressing the WT aefR $R_{N P S 3121}$ gene (Fig. 4A). The $h r p R$ promoter activity (as indicated by the hrpR-luc reporter) in the $\triangle a e f R_{N P S 3121}$ mutant was 20 to $25 \%$ of that in the WT strain (Fig. 4B). Several regulatory genes acting upstream of $h r p R S$, including $\operatorname{lonB}, \operatorname{rpoS}$, gacA, and psrA, did not show an altered expression pattern in the $\triangle a e f R_{N P S 3121}$ mutant (Fig. 4A). The activities of the reporter genes were also monitored in the bean plants. Both avrPto-luc and $h r p L-l u c$ displayed lower activities in the $\triangle a e f R_{N P S 3121} \mathrm{mu}-$ tant than in the WT strain $4 \mathrm{~h}$ after the bacteria were infiltrated into the plants (Fig. 4C and D). Consistently, the $\triangle a e f R_{N P S 3121}$ mutant infiltrated into the bean plants elicited weaker symptoms than did the WT strain (Supplementary Fig. S3). Both insertion and deletion mutants of aefR $R_{N P S 3121}$ showed approximately threefold less bacterial growth than did the WT strain 4 days after infiltration inoculation (Fig. 4E); this difference was observed consistently in four repeat experiments and was statistically significant according to $F$ test $(P<0.05)$. The aefR $R_{N P S 3121}$ mutants and the WT strain showed similar activities in the induction of HR in tobacco W38 plants (Table 2). The expression of aef $R_{N P S 3121}$ RNA was investigated in mutants corresponding to the $h r p R, h r p S, \operatorname{rhpS}, \operatorname{rhpRS}$, and lon genes (Lan et al. 2007; Xiao et al. 2007) that are known to regulate the T3 genes. None of the mutations affected the aef $R_{N P S 3121}$ RNA in $\mathrm{KB}$ medium, but deletion of the rhpRS locus moderately elevated the $a e f R_{N P S 3121}$ RNA in MM (Fig. 4F).

\section{Regulation of swarming motility and epiphytic traits by AefR NPS3121 $^{\text {. }}$}

AefR regulates epiphytic behaviors in $P$. syringae pv. syringae B728a. Mutation of aefR enhances swarming motility on semi- solid agar and invasion into leaves but reduces bacterial survival on the leaf surface (Quinones et al. 2004, 2005). These traits were examined in the $\triangle a e f R_{N P S 3121}$ mutant.

Unlike $P$. syringae pv. syringae $\mathrm{B} 728 \mathrm{a}$ and $P$. syringae $\mathrm{pv}$. tomato DC3000 that displayed clear swarming motility on semisolid agar plate, $P$. syringae pv. phaseolicola NPS3121 strain did not show swarming motility (Fig. 5A). Mutation of $a e f R_{N P S 3121}$ did not enhance swarming motility on a semisolid agar plate (Fig. 5A).

To determine whether AefR $_{\mathrm{NPS} 3121}$ regulates bacterial invasion into leaves, 2-week-old bean plants were dip-inoculated with a bacterial suspension $\left(10^{6} \mathrm{CFU} / \mathrm{ml}\right)$, each plant was covered with a plastic bag, and the numbers of bacteria inside the leaves and on the leaf surface were measured. Unlike the aefR mutant of $P$. syringae pv. syringae B728a that showed approximately 1,000-fold increase of the internal population 4 to $7 \mathrm{~h}$ after inoculation (Quinones et al. 2005), mutation of aefR $R_{N P S 3121}$ did not alter the number of bacteria inside the leaves within $28 \mathrm{~h}$ after inoculation (Fig. 5B).

$P$. syringae pv. syringae $\mathrm{B} 728 \mathrm{a}$ and the aef $R^{-}$mutant grew approximately 50-fold epiphytically after the surface-inoculated plants were incubated in moist conditions for $48 \mathrm{~h}$ (Quinones et al. 2004). After transfer into a dry environment, epiphytic population of both strains decreased approximately 20 -fold in $2 \mathrm{~h}$. The WT strain then stayed stable, but the population of the aefR $R^{-}$mutant decreased another five- to sevenfold in 50 h (Quinones et al. 2004). Unlike P. syringae pv. syringae $\mathrm{B} 728 \mathrm{a}$ and the aefR ${ }^{-}$mutant, $P$. syringae pv. phaseolicola NPS3121 and the $\triangle a e f R_{N P S 3121}$ mutant did not exhibit significant epiphytic growth after incubation inside the plastic bags for $48 \mathrm{~h}$ (Fig. 5C). After the plants were placed in the greenhouse, both strains displayed approximately twofold reduction of the epiphytic population in the first $6 \mathrm{~h}$, and then the epiphytic populations of $P$. syringae pv. phaseolicola NPS3121 and $\triangle a e f R_{N P S 3121}$ mutant increased approximately four- and sevenfold, respectively, in $48 \mathrm{~h}$ (Fig. 5C). These results indicated that AefR $\mathrm{NPS} 3121_{1}$ in $P$. syringae pv. phaseolicola $\mathrm{NPS} 3121$ and AefR in $P$. syringae pv. syringae B728a function differently under the dry environments.

In contrast with what was observed in infiltration inoculation (Fig. 4E), the internal population of the $\triangle a e f R_{N P S 3121}$
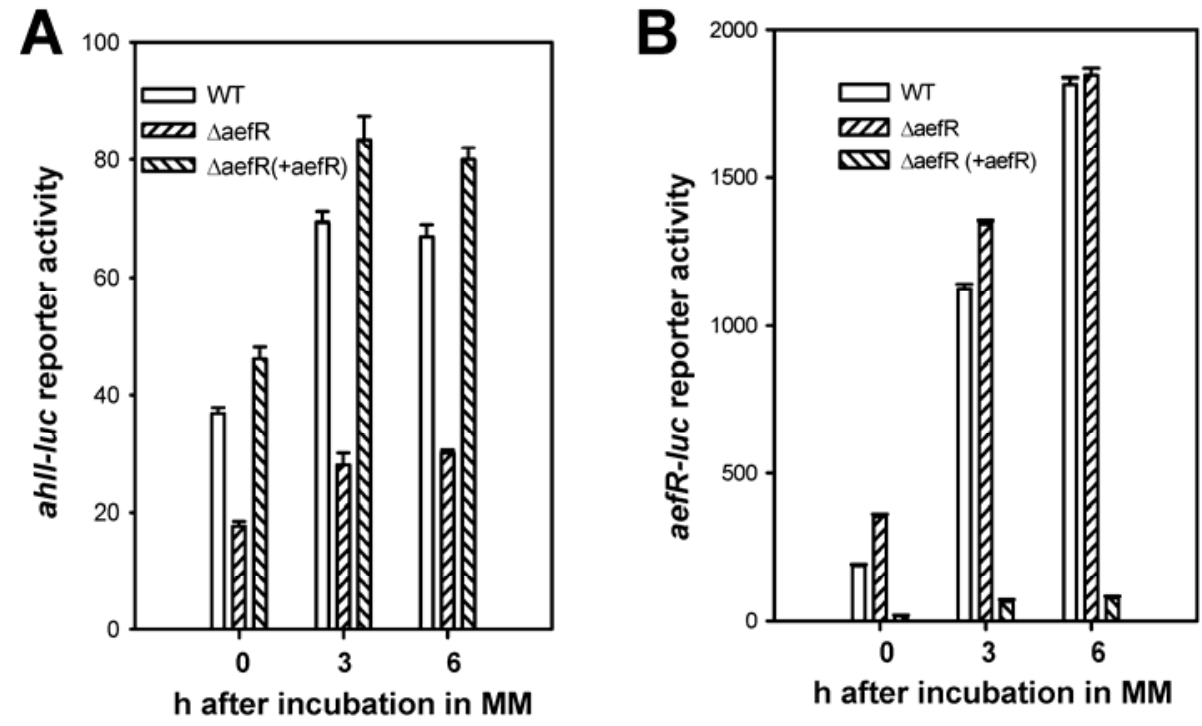

Fig. 3. Regulation of $a h l I$ and $a e f R_{N P S 3121}$ promoters by AefR $\mathrm{NPS}_{121}$. The ahlI-luc and aefR $R_{N P S 3121}$-luc reporter genes were introduced into wild-type (WT) Pseudomonas syringae pv. phaseolicola NSP3121, Aaf $_{N P S 3121}$ mutant, and $\triangle a e f R_{N P S 3121}$ mutant carrying the pML122::aefR $R_{N P S 3121}$ plasmid (for aefR $R_{N P S 3121}$ overexpression). The bacteria were grown in King's B (KB) medium and induced in minimal medium (MM) for 0 , 3 , and $6 \mathrm{~h}$ before measurement of luciferase (LUC) activities. A, Mutation of aef $R_{N P S 3121}$ reduces the $a h l I$ promoter activity in KB (indicated by 0 h) and MM. B, Overexpression of aef $R_{N P S 3121}$ inhibits its own promoter. Error bars represent standard error. 

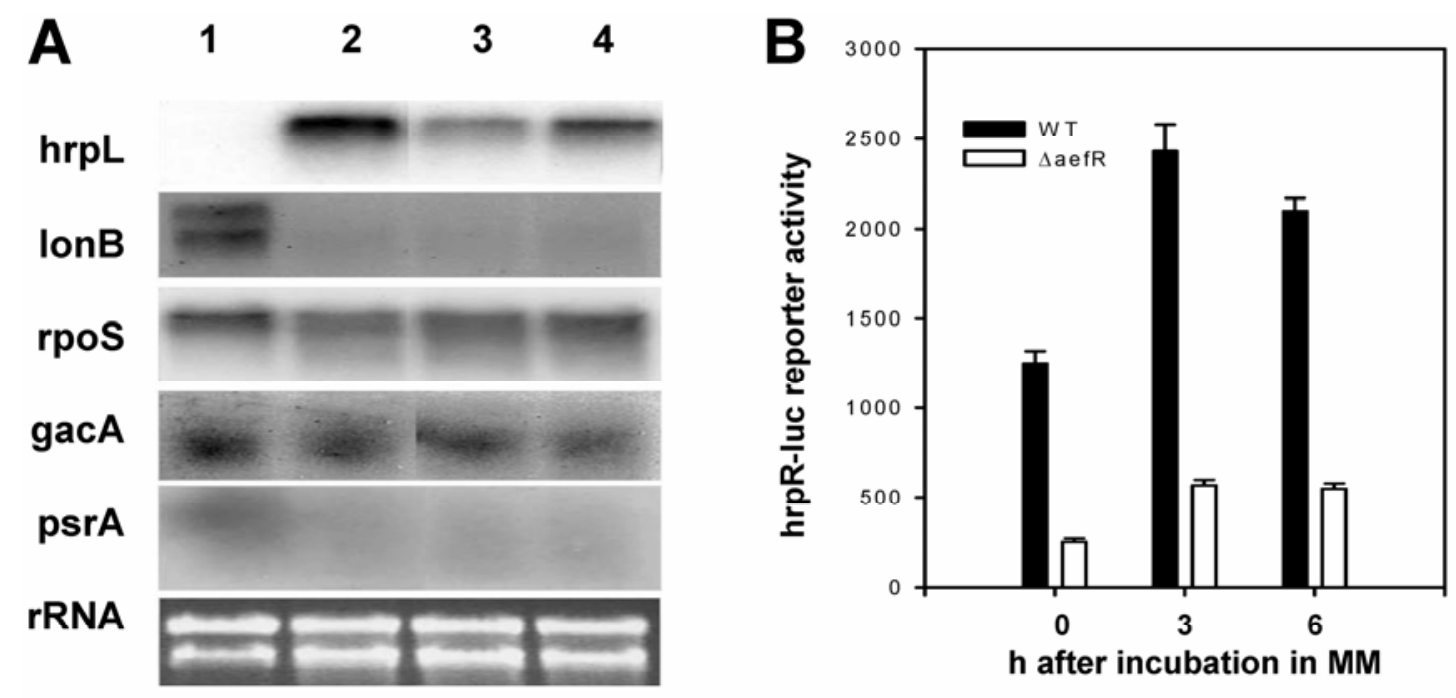

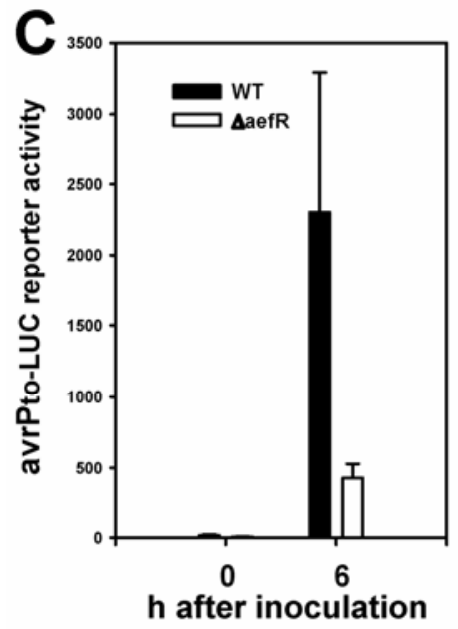

$\mathbf{F}$

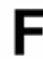

KB
D

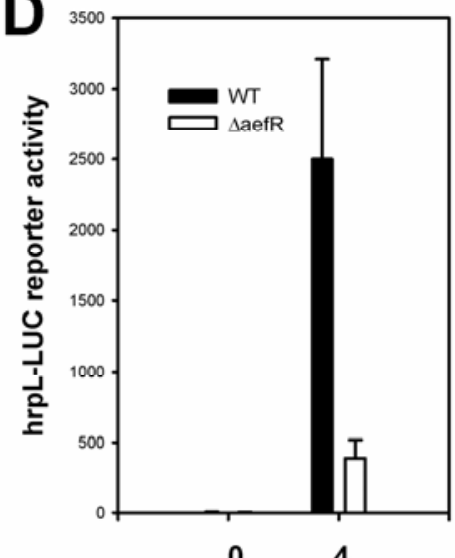

h after inoculation

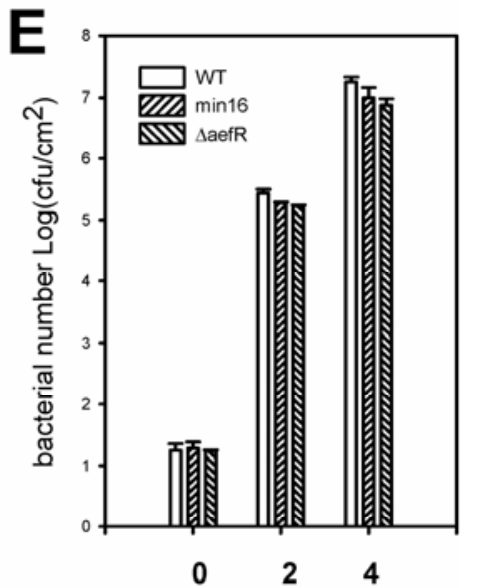

day after inoculation

MM

WT hrpR $^{-}$hrpS $^{-}$rhpS $^{-}$rhpRS $^{-}$lon

WT hrpR $^{-}$hrpS $^{-} \cdot \operatorname{rhpS}^{-} \operatorname{rhpRS}^{-}$Ion $^{-}$

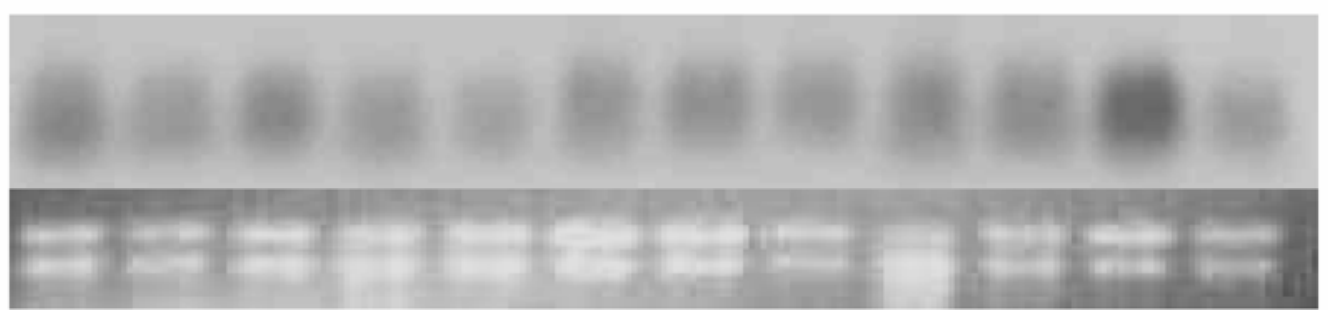

Fig. 4. Regulation of the type III secretion system and type III effector genes and pathogenicity by AefR $\mathrm{NPS} 3121_{\text {. A, Mutation of aefR }}$, duction of $h r p L$. Wild-type (WT) Pseudomonas syringae pv. phaseolicola NPS3121, $\Delta a e f R_{N P S 3121}$ mutant, and $\Delta$ aefR $R_{N P S 3121}$ mutant carrying the pML122::aefR $R_{N P S 3121}$ plasmid were grown in King's B (KB) medium and induced in minimal medium (MM) for $4 \mathrm{~h}$ before being harvested for RNA extraction. Total RNA $(10 \mu \mathrm{g})$ from each sample was analyzed by Northern blotting using DNA probes derived from the coding regions of $h r p L$, lonB, rpoS, gacA, and psrA. Loading of RNA samples is indicated by rRNA. Lane 1, WT in KB; lane 2, WT in MM; lane 3, AaefR $R_{N P S 3121}$ mutant in MM; lane 4, the complemented $\triangle a e f R_{N P S 3121}$ mutant in MM. B, Mutation of aefR $R_{N P S 3121}$ reduces the $h r p R$ promoter activity in MM. hrpR-luc reporter gene was introduced into the WT strain and $\triangle a e f R_{N P S 312 l}$ mutant. Bacteria were grown in KB and induced in MM. Luciferase (LUC) activity was measured at 0,3 , and $6 \mathrm{~h}$ after induction. Error bars indicate standard error. $\mathbf{C}$ and $\mathbf{D}$, Mutation of aefR $R_{N P S 3121}$ reduces the avrPto and hrpL promoter activities in plant. P. syringae pv. phaseolicola NPS3121 and $\triangle a e f R_{N P S 3121}$ mutant carrying $\mathbf{C}$, avrPto-luc and $\mathbf{D}$, hrpL-luc were resuspended in water to an optical density at $600 \mathrm{~nm}$ of 0.5 and infiltrated into the primary leaves of bean plants. Leaves were removed and sprayed with $1 \mathrm{mM}$ luciferin dissolved in $0.01 \%$ Tween-20, and the LUC activity was determined using a cooled charge-couple device. The experiments were repeated three times with similar results. E, Mutation of aefR $R_{N P S 3121}$ reduces the bacterial growth inside the host plants. Bacteria at $2 \times 10^{4} \mathrm{CFU} / \mathrm{ml}$ were injected into the primary bean leaves. For each data point, three leaf disks $\left(1 \mathrm{~cm}^{2}\right)$ were removed at 0,2 , and 4 days after inoculation and ground separately in sterile water for bacterial count. Error bars represent standard error. The experiment was repeated four times with similar results. The differences between the WT and mutant strains at 2 and 4 days after inoculation are significant according to $F$ test $(P<0.05)$. F, Expression of aefR $R_{N P S 3121}$ RNA in $h r p R^{-}, h r p S^{-}, r h p S^{-}, r h p R S^{-}$, and $l o n^{-}$mutants. WT P. syringae pv. phaseolicola NPS3121 and the mutant strains were grown in KB medium and induced in MM for $6 \mathrm{~h}$ before being harvested for RNA extraction. Total RNA (10 $\mu \mathrm{g})$ was analyzed by RNA blotting using probes derived from the coding region of $a e f R_{N P S 3121}$. Loading of RNA samples is indicated by rRNA. 
mutant was approximately two- to fourfold higher than the WT strain $48 \mathrm{~h}$ after dip inoculation, and the fold difference remained till the end of experiment (Fig. 5C). The better growth of the $\triangle a e f R_{N P S 3121}$ mutant on the leaf surface and inside the bean plants was observed consistently in four repeat experiments, including one experiment with an inoculum of $10^{8}$ $\mathrm{CFU} / \mathrm{ml}$. The inoculated leaves did not show water-soaked lesions but they senesced earlier than the uninoculated leaves. Leaves dip inoculated with the $\triangle a e f R_{N P S 3121}$ mutant usually senesced 1 to 2 days earlier than leaves dip inoculated with the WT strain.

\section{DISCUSSION}

We screened a total of approximately 28,000 transposontagged mutants of $P$. syringae pv. phaseolicola NPS3121 based on the compromised induction of avrPto-luc and hrpL-luc reporter genes in MM, and we isolated 46 mutant genes. The screening was approximately $5 \times$ coverage of the approximately 6-Mb $P$. syringae pv. phaseolicola genome (Joardar et al. 2005), assuming an average bacterial gene length of $1 \mathrm{~kb}$. Some of the mutants may be polar, because the mutant gene is organized in an operon with other genes. Most of the $46 \mathrm{mu}-$ tant genes encode metabolic enzymes, and only three genes encode regulatory functions. Characterization of the reporter gene activities and $h r p L$ RNA expression in the mutant strains indicated that the reporter gene activities generally reflected the T3 gene expression, indicating that the reporting systems are valid.

Many genes that were reported to regulate the T3 genes in other $P$. syringae strains were not identified in our screen. One explanation is that some of these regulatory genes do not have a regulatory function in $P$. syringae pv. phaseolicola NPS3121. Another explanation is that the regulatory genes are small in size and missed by the transposon insertion. It is also likely that the mutant screening protocol has some intrinsic defects. We used the protocol for analysis of T3 gene induction in MM for mutant screening (e.g., an individual mutant colony was picked from a $\mathrm{KB}$ plate and grown to saturation in $\mathrm{KB}$ liquid medium in 96well plates, the cells were then washed twice with MM, and the reporter genes were subsequently induced with $\mathrm{MM}$ ). Because it was impossible to pick equal quantities of bacterial cells from each mutant colony, and the growth rates of the mutants differed in $\mathrm{KB}$ medium, prolonged growth in $\mathrm{KB}$ medium was allowed to achieve saturation prior to induction in MM. However, we later found that an extended stationary phase in $\mathrm{KB}$ medium
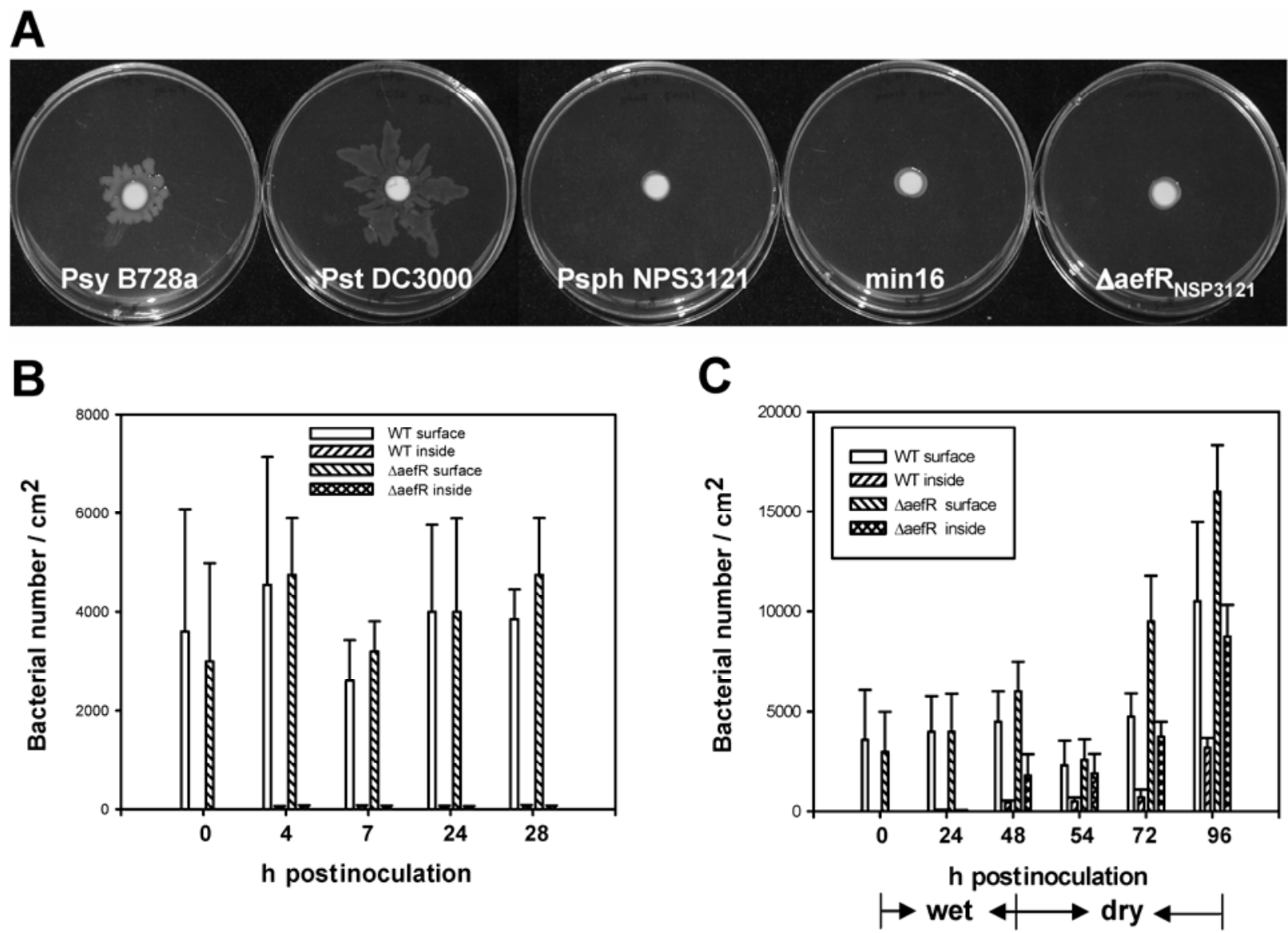

Fig. 5. Effect of aefR $R_{N P S 3121}$ mutation on bacterial motility and epiphytic fitness. A, Swarming motility on semisolid agar. Bacteria were grown in King's B $(\mathrm{KB})$ liquid overnight and resuspended in $\mathrm{KB}$ medium to an optical density at $600 \mathrm{~nm}$ of 1 . Filter disks $(6 \mathrm{~mm}$ in diameter) were soaked in bacterial suspensions and placed in the center of semisolid KB plates. Plates were photographed after incubation at $28^{\circ} \mathrm{C}$ for $24 \mathrm{~h}$. B, Bacterial invasion of bean leaves. Twoweek-old bean plants were dipped into bacterial suspension and covered with plastic bags immediately after inoculation. Surface bacteria were determined by washing the primary leaves with washing buffer in an ultrasonic bath, and the bacteria in washing solution were determined by plating on TSA plates (Xiao et al. 2007). Bacteria inside the leaves were determined by treating the washed leaves with $15 \%$ hydrogen peroxide, followed by a treatment with catalase. Leaves were then macerated in sterile potassium phosphate buffer for bacterial count. Population sizes of wild-type (WT) and aefR $R_{N P S 3121}{ }^{-}$mutant are not significantly different according to $F$ test. C, Epiphytic fitness assay. Two-week-old bean plants were dip inoculated and covered with plastic bags immediately after inoculation. The plants were removed from the plastic bags $48 \mathrm{~h}$ after inoculation and placed in the greenhouse. The numbers of bacteria on leaf surface and inside the leaves were determined as described in B. Epiphytic population of the WT and the aefR $R_{N P S 3 I 2 I}{ }^{-}$mutant are not significantly different at $0,24,48$, and $54 \mathrm{~h}$ postinoculation (hpi) but are significantly different at $72 \mathrm{hpi}$ according to $F$ test $(P<0.05)$. The internal bacterial numbers are significantly different after 48 hpi. Error bars indicate standard error. Experiments of B and C were repeated four times with similar results. 
reduced the induction of avrPto-luc and hrpL-luc reporter genes in MM (X. Deng and X. Tang, unpublished results). This practice, albeit enabling a uniform number of cells to be compared, narrowed the difference between strains showing WT levels of induction and mutants showing partial induction of the reporter genes. Washing to remove KB medium from the culture before induction of the reporter genes is another step that may affect identification of partial mutants. Contamination of MM with a small amount of KB medium significantly reduced the induction of the reporter genes in P. syringae pv. phaseolicola NPS3121, However, it was technically difficult to completely remove KB medium from all the microtiter wells, and the residual amount of $\mathrm{KB}$ medium could inhibit the induction of the reporter genes. We also noticed bacterial loss when supernatant was discarded from the plate after centrifugation. Because both residual $\mathrm{KB}$ medium and bacterial loss caused variations among strains in the plate, we set criteria to select mutants with a LUC activity $\leq 20 \%$ of the majority of other strains in the same plate. It is apparent that these intrinsic problems of the screening protocol discriminated against the selection of mutants with partial induction of the reporter genes.

The mutant screening experiments conducted by us and by Hendrickson and associates (2000) indicated that as much as 4 to $5 \%$ of $P$. syringae mutants showed reduced induction of the T3 genes in MM. To identify the regulatory genes from the large pool of candidate mutants was a major obstacle. We deployed the two-stage semidegenerated PCR method (Jacobs et al. 2003) to determine the transposon insertion sites in $84 \mathrm{mu}-$ tants that were identified using the avrPto-luc reporter. Most of these mutant genes encode metabolic enzymes. Although these genes provide little insight into the regulatory mechanisms, they do reveal the nature of $P$. syringae mutations that compromise the induction of the T3 genes in MM. These results led us to test whether bacterial growth assays in MM can differentiate metabolic mutants from regulatory mutants. We found that all metabolic mutants showed no or poor growth, whereas all regulatory mutants grew normally in MM. Therefore, we added this procedure to the mutant screening protocol. This procedure eliminated all metabolic mutants from the pool of candidate mutants that were identified using the $h r p L$ $l u c$ reporter and significantly enhanced the efficiency of isolation of regulatory genes. However, regulatory genes which are also required for bacterial growth in MM would be excluded by this procedure.

Pathogenicity assays indicated that the level of T3 gene expression in many metabolic mutants in MM was not correlated with their pathogenicity in host plants. In fact, a large number of metabolic mutants were almost as pathogenic as the WT strain, although they displayed no induction of the T3 genes in MM. The pathogenicity of most metabolic mutants was correlated with the abundance of the corresponding metabolites in the apoplastic fluid (Rico and Preston 2008; Ritte et al. 1999; Solomon and Oliver 2002; Tanaka and Tanaka 2007), indicating that nutrient auxotroph plays a critical role in the induction of T3 genes in plants and bacterial pathogenicity. The pathogenicity of most metabolic mutants was correlated with their HR-inducing activity, which is consistent with the fact that apoplastic fluids in different plant species are similar in nutrient compositions (Rico and Preston 2008; Solomon and Oliver 2002).

The only novel regulatory gene identified in our screen was aefR $R_{N P S 3121}$. AefR in P. syringae pv. syringae $\mathrm{B} 728$ a regulates the AHL signal by upregulating the ahlI promoter, and it autoinhibits its own promoter (Quinones et al. 2004). Both functions were observed with AefR $_{\mathrm{NPS} 3121}$, suggesting that AefR $_{\mathrm{NPS} 3121}$ is orthologous to AefR in P. syringae pv. syringae B728a. The role of AefR in regulating the T3 genes was not reported, although the $a e f R^{-}$mutant was found to cause smaller disease lesions than did $P$. syringae pv. syringae B728a when injected into bean pods (Quinones et al. 2005). We found that mutation of aefR $R_{N P S 3121}$ reduced the induction of T3 genes and the bacterial pathogenicity when bacteria were injected into the bean plants. Because induction of the T3 genes is essential for bacterial pathogenesis, the reduced T3 gene induction in the aefR $R_{N P S 3121}{ }^{-}$mutant is probably responsible for the reduced pathogenicity. $P$. syringae pv. phaseolicola NPS3121 and the $a e f R_{N P S 3121}^{-}$mutant did not show a clear difference in the HR. A possible explanation is that HR is sensitive, and a partial induction of the $\mathrm{T} 3$ genes is sufficient for the elicitation of a full HR. The finding that $A_{\text {efR }} \mathrm{NPS}_{3121}$ regulates both the quorum-sensing signal and T3 genes is exciting and suggests that $P$. syringae pv. phaseolicola NPS3121 may regulate the T3 genes in response to cell density. Quorum-sensing signals are known to regulate the production of exoenzymes and exopolysaccharides, two major virulence factors, in numerous plant-pathogenic bacteria (Von Bodman et al. 2003) but its role in regulating the T3 genes has not been well documented in $P$. syringae. Our studies showed that AefR $_{\mathrm{NPS} 3121}$ regulates the $\mathrm{T} 3$ genes, possibly by modulating the $h r p R$ promoter activity. It remains to be determined whether AefR NPS3121 $_{1}$ regulates the $h r p R$ promoter directly by binding to the promoter or indirectly via the AHL-mediated signaling pathway.

Although AefR of $P$. syringae pv. syringae B728a and AefR $_{\mathrm{NPS} 3121}$ act similarly in regulating AHL synthesis, the respective mutants exhibit significant difference in several epiphytic traits that are proposed to be regulated by AHL in $P$. syringae pv. syringae B728a (Quinones et al. 2004, 2005). Compared with $P$. syringae pv. syringae $\mathrm{B} 728 \mathrm{a}$, the aefR $R^{-}$mutant is hypermotile on semisolid agar and invades leaves more rapidly (Quinones et al. 2005). The hypermotility on semisolid agar was assumed to be related to the more rapid invasion of leaves (Quinones et al. 2005). Unlike $P$. syringae pv. syringae $\mathrm{B} 728 \mathrm{a}$ and $P$. syringae pv. tomato DC3000, P. syringae pv. phaseolicola NPS3121 did not show visible swarming motility on semisolid agar, and mutation of aefR $R_{N P S 3121}$ did not enhance the swarming motility. Nonetheless, both $P$. syringae pv. phase-

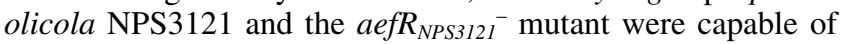
invading bean leaves following dip inoculation. However, the two strains displayed similar rates of invasion, as indicated by the similar numbers of internal bacteria 4 to $28 \mathrm{~h}$ after dip inoculation (Fig. 5B and C). This result indicated that AefR $_{\mathrm{NPS} 3121}$ did not play a major role in regulating $P$. syringae pv. phaseolicola NPS3121 invasion into bean leaves.

$P$. syringae pv. syringae $\mathrm{B} 728 \mathrm{a}$ and the aefR $R^{-}$mutant grew approximately 50 -fold on bean leaf surfaces within 2 days under the moist conditions, and a short exposure to a dry environment reduced the epiphytic population by 20- to 50-fold. Extended incubation in the dry conditions further reduced the epiphytic population, and mutation of aefR rendered the epiphytic bacteria more susceptible to the stress (Quinones et al. 2004). Different from $P$. syringae pv. syringae B728a and the aefR $R^{-}$mutant, $P$. syringae pv. phaseolicola NPS3121 and the aef $R_{N P S 3121^{-}}$mutant did not grow significantly on bean leaf surface under the moist conditions, and a short exposure to the dry conditions reduced the epiphytic population only by approximately twofold. Interestingly, both strains grew slowly on leaf surface after the small reduction of the epiphytic population in the dry environment (Fig. C). These results indicated that $\mathrm{AefR}_{\mathrm{NPS} 3121}$, like AefR, does not affect bacterial growth under moist environment conditions. However, under the dry conditions, AefR positively regulates the epiphytic survival of $P$. syringae pv. syringae B728a, whereas AefR NPS3121 $_{1}$ negatively regulates the epiphytic growth of $P$. syringae pv. phaseolicola NPS3121. The remarkable difference of AefR and 
AefR $_{\text {NPS3121 }}$ in modulating the epiphytic behaviors of their respective bacteria suggested that the epiphytic associations of $P$. syringae pv. phaseolicola NPS3121 and $P$. syringae pv. syringae $\mathrm{B} 728 \mathrm{a}$ with their host plants involve different mechanisms.

Although the aefR ${ }_{N P S 3121}^{-}$mutant is less pathogenic than the WT strain after infiltration into bean plants, it is more pathogenic than the WT strain following dip inoculation, as indicated by the larger aefR $R_{N P S 3121^{-}}$mutant population inside the leaves at the end of experiment (Fig. 5C) and the earlier senescence of the inoculated leaves. Similar results were also reported for the aefR $R^{-}$mutant that elicited more disease lesions on bean leaves if the spay-inoculated plants were incubated in moist conditions for more than $48 \mathrm{~h}$ before being placed in a dry environment (Quinones et al. 2005). It was proposed that more aefR $R^{-}$mutant cells entered the leaves during the incubation, which caused more severe symptoms (Quinones et al. 2005). Indeed, we detected a larger internal population of the aef $_{N P S 3121^{-}}$mutant $48 \mathrm{~h}$ after incubation in the moist conditions (Fig. 5C). Two possible routes could lead to the larger internal population. i) Although the aefR $R_{N P S 3121^{-}}$mutant was not found to enter the leaves more rapidly during the first $24 \mathrm{~h}$ of incubation, the mutant might enter the leaves more rapidly during the later hours under the moist conditions. ii) Although infiltrated $P$. syringae pv. phaseolicola NPS3121 grew better than did the aef $R_{N P S 3121}{ }^{-}$mutant in the greenhouse, the aef $R_{N P S 3121^{-}}$mutant may grow better than the WT strain under the wet conditions. In addition to the larger internal population gained in the wet conditions, we noticed that the aefR $R_{N P S 3121}$ mutant produced a larger epiphytic population in the greenhouse (Fig. 5C), which may allow more bacterial cells to enter the leaves during the prolonged interaction with the plants. Other than these scenarios, it should be pointed out that infiltration-inoculation and surface-inoculation are different biological processes. We cannot rule out the possibility that $\operatorname{AefR}_{\mathrm{NPS} 3121}$ has a positive role in regulating bacterial pathogenicity following infiltration inoculation but a negative role following surface inoculation.

\section{MATERIALS AND METHODS}

Plant materials and culture media.

Bean (Phaseolus vulgaris cv. Red Kidney) plants and tobacco W38 plants were used for pathogenicity and HR assays, respec- tively. Plant materials were grown in a greenhouse as described previously (Xiao et al. 2007). Escherichia coli strains were cultured in Luria-Bertani medium at $37^{\circ} \mathrm{C}$. Pseudomonas syringae bacteria were cultured in KB medium (King et al. 1954) at room temperature. Induction of T3SS was performed at room temperature in $\mathrm{MM}\left(50 \mathrm{mM} \mathrm{KH_{2 }} \mathrm{PO}_{4}, 7.6 \mathrm{mM}\right.$ $\left(\mathrm{NH}_{4}\right)_{2} \mathrm{SO}_{4}, 1.7 \mathrm{mM} \mathrm{MgCl} 2,1.7 \mathrm{mM} \mathrm{NaCl}$, and $10 \mathrm{mM}$ fructose, $\mathrm{pH}$ 5.7) (Huynh et al. 1989). Bacteria were plated on TSA plates (Xiao et al. 2007) for counting of CFU. Antibiotics for selection of $P$. syringae strains were rifampcin, $25 \mathrm{mg} / \mathrm{liter}$; kanamycin, $10 \mathrm{mg} /$ liter; spectinomycin, $50 \mathrm{mg} / \mathrm{liter}$; tetracycline, $10 \mathrm{mg} /$ liter; and gentamycin, $10 \mathrm{mg} / \mathrm{liter}$. Antibiotics for selection of $E$. coli were ampicillin, $\mathrm{mg} / \mathrm{liter} 100$; kanamycin, $50 \mathrm{mg} /$ liter; spectinomycin, $100 \mathrm{mg} / \mathrm{liter}$; and gentamycin, 20 $\mathrm{mg} / \mathrm{liter}$.

\section{Plasmids.}

Plasmids and primers are listed in Tables 3 and 4, respectively. To construct the reporter gene for the aefR $R_{N S P 3121}$ promoter, the luc gene was released from pHM2::avrPto-luc by $B a m \mathrm{HI}$ and $X b a \mathrm{I}$ digestion and ligated into pBluescript$\mathrm{SK}(+)$, resulting in pBluescript-SK-luc. The promoter of

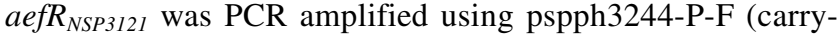
ing EcoRI) and pspph3244-P-R (carrying BamHI) as primers and $P$. syringae pv. phaseolicola NPS3121 genomic DNA as template. The PCR product was digested with EcoRI and Bam HI and cloned into pBluescript-SK-luc, resulting in pBS-aefR $R_{N S P 3121}$-luc. After sequencing, the EcoRI and XbaI fragment in pBS-aefR $R_{N S P 312 I^{-}}$luc was released and then cloned into pHM2, resulting in pHM2::aefR ${ }_{N S P 312 I^{-}} l u c$ for the $a e f R_{N S P 3121}$ promoter assay. The same strategy was used to generate the reporter gene for the ahlI (PSPPH_1614) promoter. The ahlI promoter was PCR amplified using pspph1614-P-F and pspph1614-P-R as primers.

To construct the hrpR-luc reporter gene, a 1-kb fragment of the $h r p R$ promoter was amplified using primers psph-hrpR-PF and psph-hrpR-PR. The PCR product was digested with EcoRI and BamHI, cloned into pBluescript-SK(+) plasmid, and sequence confirmed. The promoter DNA was then released from the plasmid with EcoRI/BamHI digestion and cloned upstream of the luc gene in the pPTE6::luc plasmid (Xiao et al. 2004) to generate pPTE6::hrpR-luc. To generate pLT::hrpR-luc, the kanR gene in pPTE6::hrpR-luc plasmid was knocked out by EZ-Tn5<TET-1 $>$ transposon insertion.

Table 3. Plasmids

\begin{tabular}{lll}
\hline Plasmids & \multicolumn{1}{c}{ Description } & References \\
\hline pBluescript-SK(+) & Cloning and sequencing & Stratagene, La Jolla, CA, U.S.A. \\
pGEM-7Z & Cloning and sequencing & Promega Corp., Madison, WI, U.S.A. \\
pGEM-T & Cloning and sequencing & Promega Corp., Madison, WI, U.S.A. \\
pML122 & Broad-host plasmid & Labes et al. 1990 \\
pHM2 & Broad-host plasmid & Xiao et al. 2007 \\
pHM2::avrPto-luc & avrPto-luc reporter in pHM2 & Xiao et al. 2007 \\
pHM2::hrpL-luc & hrpL-luc reporter in pHM2 & Xiao et al. 2007 \\
pPTE6::luc & Firefly luciferase in pPTE6 & Xiao et al. 2004 \\
pBS-hrpR & Intermediate construct for pLT-hrpR-luc & This study \\
pPTE6::hrpR-luc & hrpR-luc in pPTE6 & This study \\
pLT::hrpR-luc & Derived from pPTE6::hrpR-luc by EZ-Tn5<TET-1>insertion & This study \\
pGEM-T-PSPPH_3244 & Intermediate construct for pML122::PSPPH_3244 & This study \\
pML122::PSPPH_3244 & PSPPH_3244 in pML122 plasmid, under pNm promoter & This study \\
pBluescript-SK-luc & Firefly luciferase in pBluescript-SK(+) & This study \\
pBS-PSPPH_3244-luc & Intermediate construct for pHM2-PSPPH_3244-luc & This study \\
pBS-PSPPH_1614-luc & Intermediate construct for pHM2-PSPPH_1614-luc & This study \\
pHM2::PSPPH_3244-luc & PSPPH_3244-luc reporter in pHM2 & This study \\
pHM2::PSPPH_1614-luc & PSPPH_1614-luc reporter in pHM2 & This study \\
p7Z::PHPPH_3244FR & Intermediate construct for marker exchange & This study \\
p7Z::FKanR & Intermediate construct for marker exchange & This study \\
pHM1::PSPPH_3244-FKanR & For maker exchange & This study \\
\hline
\end{tabular}


To construct pML122::aefR $R_{N S P 3121}$, the coding region of $a_{\text {efR }} R_{N S 3121}$ was PCR amplified using primers pspph3244-O-F (carrying XhoI) and pspph3244-O-R (carrying ClaI). The PCR fragment was cloned into pGEM-T and confirmed by sequencing. The fragment was then released by XhoI and ClaI digestion and cloned into pML122, resulting in pML122::aefR $R_{N S P 3121}$ for aef $R_{N S P 3121}{ }^{-}$mutant complementation and aef $R_{N S P 3121}$ overexpression.

\section{Mutant screen.}

The transposon insertion mutant library was constructed in $P$. syringae pv. phaseolicola NPS3121 strain carrying the pHM2:: avrPto-luc and pHM2::hrpL-luc reporter plasmids as described previously (Xiao et al. 2007). Mutant colonies grown on KB plates containing rifampcin, kanamycin, and spectinomycin were picked with sterile toothpicks into $100 \mu \mathrm{l}$ of liquid $\mathrm{KB}$ medium containing the same antibiotics in 96-well plates and cultured for $36 \mathrm{~h}$ until complete saturation. The 96-well plates were centrifuged, and the bacteria were washed twice with MM and resuspended in $500 \mu \mathrm{l}$ of MM. After induction in MM for 6 $\mathrm{h}, 100 \mu \mathrm{l}$ of cell suspension was transferred from each sample to a new 96-well plate and mixed with $10 \mu \mathrm{l}$ of $0.1 \mathrm{mM}$ luciferin. LUC activity was measured using a cooled charge-couple device (CCD, Roper Scientific, Trenton, NJ, U.S.A.). Mutants with approximately $20 \%$ LUC activity relative to the other clones in the same plate were selected as putative mutants. These mutants were confirmed for the induction of reporter genes in MM as described previously (Xiao et al. 2007).

Table 4. Primers

\begin{tabular}{ll}
\hline Primer names & \multicolumn{1}{c}{ Sequences } \\
\hline pspph3244-O-F & TTCTCGAGTGGCAACAAGTAAACTGCTGA \\
pspph3244-O-R & TTATCGATGGGGCGTAGTACTCGACGTA \\
pspph3244-P-F & TTGAATTCCGGTTTCCATCAGTGTCAG \\
pspph3244-P-R & TTGGATCCCATAGGTTCGCTTCAAACGGA \\
pspph1614-P-F & TTGAATTCGCAGTATCTGGCCACTT \\
psph1614-P-R & TTGGATCCCATTATAAACTCCACTC \\
p3244LF & TTTCTAGAACGCAGGTATAGGACGCAGT \\
p3244LR & TTGGATCCGATGGATTCGCGTTTCTGAT \\
p3244RF & TTGGATCCGAACATGTTCTGGGCTGGT \\
p3244RR & TTGAGCTCGCCAATCCACGTGATTTCT \\
Kan-BF & TTGGATCCCATCGATGAATTGTGTCT \\
Kan-BR & TTGGATCCGGTGGACCAGTTGGTGAT \\
Psph-hrpR-PF & GAATTCGTTTTAAAGCCGGATGTATAG \\
Psph-hrpR-PR & TTGGATCCGTCCATATCCAGAAACGC \\
psph-hrpL-NF & GACTCTTCGTCTGCCGGTAT \\
psph-hrpL-NR & GGGTCAATCTGCTGCTTCAA \\
psph-gacA-NF & CATAGACGGTCTGCAGGTTG \\
psph-gacA-NR & GTGACGTACAGCGAGCAAAG \\
psph-rpoS-NF & AAGGAAGCGTCAAACGAGAA \\
psph-rpoS-NR & AGCCCGTTCTTTCAAGGAT \\
psph-rpoN-NF & CGCCTTACTCCAGCTTTCCAC \\
psph-rpoN-NR & GTCGCCGTACTCAAGAAAGC \\
psph-psrA-NF & CGTTGAACGCATTCTTGATG \\
psph-psrA-NR & GATCATGGTCGGGTCACTG \\
psph-ahlI-NF & GAGCGGGTTTGAGTTTCAGT \\
psph-ahlI-NR & AGCAGGTCATCCGTGACAG \\
psph-lonB-NF & GATTCGTGGCCCGTACTGT \\
psph-lonB-NR & TGGATATGCGTGTCGTGTTT \\
Kan2-SP1 & GATAGATTGTCGCACCTGATTG \\
Kan2-SP2 & AAGACGTTTCCCGTTGAATATG \\
Kan2-SP3 & GCAATGTAACATCAGAGATTTTGAG \\
CEKG 2A & GGCCACGCGTCGACTAGTACNNNNNNNNNNA \\
& GAG \\
CEKG 2B & GGCCACGCGTCGACTAGTACNNNNNNNNNNA \\
CEKG 2C & CGCC \\
& GGCCACGCGTCGACTAGTACNNNNNNNNNNG \\
CEKG 4 & ATAT \\
HrpL-FLAG-F & TGCCACGCGTCGACTAGTAC \\
HrpL-FLAG-R & CCTTCGAAGGGCTGTGGTCAGCCCGTG \\
\hline &
\end{tabular}

Measurement of reporter gene activities in $\mathrm{MM}$ and in the plant.

Bacteria were grown in liquid $\mathrm{KB}$ medium containing rifampicin and spectinomycin to an optical density at $600 \mathrm{~nm}\left(\mathrm{OD}_{600}\right)$ of 2.0 to 2.5. To induce the reporter genes in MM, bacteria were washed twice with $\mathrm{MM}$, resuspended in $\mathrm{MM}$ to $\mathrm{OD}_{600}=0.1$, and incubated for $4 \mathrm{~h}$ for the induction of hrpL-luc and $6 \mathrm{~h}$ for the induction of avrPto-luc. Cell suspension $(100 \mu \mathrm{l})$ was mixed with $10 \mu \mathrm{l}$ of $0.1 \mathrm{mM}$ luciferin, and the LUC activity was measured using a cooled CCD (Roper Scientific). After LUC measurement, the bacteria were diluted and plated on TSA plates for counting of CFU. The relative LUC activity was normalized to the numbers of bacteria in MM. To induce the reporter genes in the plant, bacteria were washed twice with sterile water, resuspended in sterile water to $\mathrm{OD}_{600}=0.5$, and infiltrated into the primary leaves of 2-week-old bean plants. The inoculated leaves were excised 4 and $6 \mathrm{~h}$ after inoculation for measurement of hrpL-luc and avrPto-luc reporter activities, respectively. The excised leaves were sprayed with $1 \mathrm{mM}$ luciferin dissolved in $0.01 \%$ Tween-20, and the LUC activity was determined using a cooled CCD (Roper Scientific). After LUC measurement, the number of bacteria inside the inoculated leaves was measured as described previously (Xiao et al. 2007) and the relative LUC activity was normalized to the bacterial number inside the leaves. Each data point represents an average of three to four replicates. Each experiment was repeated three to five times with similar results.

\section{Mapping of transposon insertion sites.}

The transposon insertion sites were determined by a twostage semidegenerated PCR according to Jacobs and associates (2003) using two transposon-specific primers (Kan2-SP1 and Kan2-SP2) and four degenerated primers (CEKG 2A, CEKG 2B, CEKG 2C, and CEKG). The PCR product was sequenced using the third transposon-specific primer Kan2-SP3. Sequences flanking the transposon DNA were searched against the $P$. syringae pv. phaseolicola 1448A genome sequence using Blastn. The mutant genes of $P$. syringae pv. phaseolicola NSP3121 were distinguished from the $P$. syringae pv. phaseolicola 1448 A genes by adding a subscript "NSP312I".

\section{Assay of bacterial growth in MM.}

Mutant colonies were grown in $\mathrm{KB}$ medium to $\mathrm{OD}_{600}=2.5$. Bacterial cells were collected by centrifugation, washed twice with MM, and resuspended in MM. The bacteria were diluted in $\mathrm{MM}$ to $\mathrm{OD}_{600}=0.1$ and grown at room temperature for $36 \mathrm{~h}$ with constant shaking at $250 \mathrm{rpm}$. The bacterial density was determined using a spectrophotometer.

\section{Infiltration inoculation and HR assay.}

Preparation of bacterial inoculum for plant inoculation was as described previously (Shan et al. 2000). Bacteria at $2 \times 10^{4}$ $\mathrm{CFU} / \mathrm{ml}$ were hand injected into the primary leaves of 2-weekold bean plants for pathogenicity assays. Disease symptoms on bean leaves were documented 5 days after inoculation. For bacterial growth assays, leaf disks $\left(1 \mathrm{~cm}^{2}\right)$ were removed at 0 , 4 , or 6 days after inoculation and ground in sterile water. Bacteria were diluted to proper concentration and plated on a TSA plate containing rifampicin at $30 \mathrm{mg} / \mathrm{liter}$ (Xiao et al. 2007) for bacterial count. For HR assay, bacteria at $10^{8} \mathrm{CFU} / \mathrm{ml}$ were injected into the fully expanded tobacco W38 leaves. At $8 \mathrm{~h}$ after injection, death of the inoculated area was visually examined hourly.

\section{Motility assay.}

Swarming motility was assessed on semisolid $\mathrm{KB}$ plates containing $0.4 \%$ agar, as described by Quinones and associates 
(2005). Cells were grown in $\mathrm{KB}$ liquid overnight and resuspended in $\mathrm{KB}$ to $\mathrm{OD}_{600}=1$. Filter disks $(6 \mathrm{~mm}$ in diameter $)$ were soaked in bacterial suspensions and placed in the center of the plate. Plates were then incubated at $28^{\circ} \mathrm{C}$ for $24 \mathrm{~h}$ before photography.

The procedures described by Quinones and associates (2005) were used to determine the ability of bacteria to enter the interior of leaves. Two-week-old bean plants were dipped into a bacterial suspension of $1 \times 10^{6} \mathrm{CFU} / \mathrm{ml}$ in $10 \mathrm{mM}$ potassium phosphate buffer (PB), $\mathrm{pH} 7.0$, plus Silwet at $50 \mu \mathrm{l} /$ liter for $1 \mathrm{~min}$. The plants were covered with plastic bags immediately after dip inoculation to maintain humidity. Primary leaves were excised at various times and surface sterilized with $15 \%$ hydrogen peroxide for $10 \mathrm{~min}$, followed by a treatment with catalase at $7.5 \mu \mathrm{g} / \mathrm{ml}$ for $10 \mathrm{~min}$. Leaves were then macerated in sterile PB and the released bacteria were plated on a TSA plate containing rifampicin at $30 \mathrm{mg} / \mathrm{liter}$ for counting of CFU. The number of bacteria was normalized according to the surface area of leaves. Each experiment was repeated at least three times with similar results.

\section{Epiphytic fitness assay.}

Two-week-old bean plants were dipped into a bacterial suspension $\left(1 \times 10^{6} \mathrm{CFU} / \mathrm{ml}\right.$ in PB plus Silwet at $50 \mu \mathrm{l} /$ liter $)$ for 1 min. Plants were covered with plastic bags immediately after dip inoculation, removed from the plastic bag $48 \mathrm{~h}$ after inoculation, and placed in the greenhouse. Primary leaves were excised at various times after inoculation and immersed individually into $50 \mathrm{ml}$ of washing buffer $(100 \mathrm{mM}$ potassium phosphate buffer containing $0.1 \%$ Bacto-peptone) in a plastic tube. The plastic tubes were sonicated in an ultrasonic bath for $7 \mathrm{~min}$ and vortexed briefly to wash off the surface bacteria. Bacteria in washing solution were plated on a TSA plate containing rifampicin at $30 \mathrm{mg} / \mathrm{liter}$ for bacterial count. To measure the bacteria inside the leaves, the leaves were further treated with $15 \%$ hydrogen peroxide for $10 \mathrm{~min}$, followed by a treatment with catalase at $7.5 \mu \mathrm{g} / \mathrm{ml}$ for $10 \mathrm{~min}$. Leaves were then macerated in sterile $\mathrm{PB}$, and the released bacteria were plated on a TSA plate containing rifampicin at $30 \mathrm{mg} / \mathrm{liter}$ for bacterial count. The numbers of bacteria were normalized according to the surface area of leaves. Each experiment was repeated at least three times with similar results.

\section{RNA extraction and Northern blotting.}

Bacterial RNA was extracted using a modified hot phenol method (Lan et al. 2006). DNase I (Promega Corp., Madison, WI, U.S.A.) treatment was used to remove the contaminating DNA in RNA samples. Total RNA $(10 \mu \mathrm{g})$ was used for Northern blotting. The hrpL, rpoS, psrA, lonB, gacA, and aef $_{N P S 3121}$ coding regions were PCR amplified using primers listed in Table 4 and radiolabeled with ${ }^{32} \mathrm{P}$ dCTP using the Random Primed DNA Labeling kit (Ambion, Austin, TX, U.S.A.) as probes. Procedures described by Tang and associates (1999) were followed for hybridization and washing.

\section{Construction of $\triangle a e f R_{N P S 3121}$ mutant.}

A 1.8-kb DNA fragment upstream of aefR $R_{N P S 3121}$ was PCR amplified using primers P3244LF and P3244LR (Table 4,

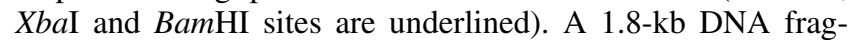
ment downstream of aefR $R_{N P S 3121}$ was PCR amplified using primers P3244RF and P3244RR (Table 4, BamHI and SacI sites are underlined). The PCR products were digested with $X b a \mathrm{I} /$ Bam HI and BamHI/SacI, respectively, and cloned into the $X b a \mathrm{I}$ and $S a c \mathrm{I}$ sites of pGEM-7Z, resulting in p7Z3244FR. A DNA fragment containing the kanamycin resistance gene was PCR amplified from EZ::Tn $<\mathrm{KAN}-2>$ (Epicentre Technologies, Madison, WI, U.S.A.), using primers
Kan-BF and Kan-BR (Table 4, BamHI sites underlined), digested with BamHI, and cloned into the BamHI site of p7Z3244FR, resulting in p7Z-3244FkanR. The XbaI and SacI fragment in p7Z-3244FkanR was cloned into pHM1, and the resulting $\mathrm{pHM} 1:: 3244 \mathrm{FkanR}$ plasmid was introduced into $P$. syringae pv. phaseolicola NPS3121 for marker exchange. Colonies sensitive to spectinomycin but resistant to kanamycin were further verified by PCR and Southern blotting using DNA probes derived from the $a e f R_{N P S 3121}$ coding region.

\section{Western blot analysis.}

Bacteria grown in $\mathrm{KB}$ and $\mathrm{MM}$ media were adjusted with corresponding medium to $\mathrm{OD}_{600}=1$. Bacteria $(30 \mu \mathrm{l})$ was boiled in $1 \times$ sodium dodecyl sulfate (SDS) sample buffer and loaded to an SDS polyacrylamide gel electrophoresis gel. Western blot was performed as described (Shan et al. 2000) with the anti-LUC antibodies (NeoMarkers, Fremont, CA, U.S.A.).

\section{ACKNOWLEDGMENTS}

We thank B. Valent and F. White for their critical reading of the manuscript. The work was supported by USDA NRI grants 2003-35319-13246 and 2005-35319-15299. Kansas Agriculture Experimental Station contribution number 08-292-J.

\section{LITERATURE CITED}

Alfano, J. R., and Collmer, A. 2004. Type III secretion system effector proteins: Double agents in bacterial disease and plant defense. Annu. Rev. Phytopathol. 42:385-414.

Bretz, J., Losada, L., Lisboa, K., and Hutcheson S. W. 2002. Lon protease functions as a negative regulator of type III protein secretion in Pseudomonas syringae. Mol. Microbiol. 45:397-409.

Brooks, D. M., Hernández-Guzmán, G., Kloek, A. P., Alarcón-Chaidez, F., Sreedharanm A., Rangaswamy, V., Peñaloza-Vázquez, A., Bender, C. L., and Kunkel, B. N. 2004. Identification and characterization of a well-defined series of coronatine biosynthetic mutants of Pseudomonas syringae pv. tomato DC3000. Mol. Plant-Microbe Interact. 17:162-174.

Cabedo, H., Macian, F., Villarroya, M., Escudero, J. C., Martinez-Vicente, M., Knecht, E., and Armengod, M. E. 1999. The Escherichia coli trmE (mnmE) gene, involved in tRNA modification, codes for an evolutionarily conserved GTPase with unusual biochemical properties. EMBO (Eur. Mol. Biol. Organ.) J.18:7063-7076.

Chatterjee, A., Cui, Y., Yang, H., Collmer, A., Alfano, J. R., and Chatterjee, A. K. 2003. GacA, the response regulator of a two-component system, acts as a master regulator in Pseudomonas syringae pv. tomato DC3000 by controlling regulatory RNA, transcriptional activators, and alternate sigma factors. Mol. Plant-Microbe Interact. 16:1106-1117.

Chatterjee, A., Cui, Y., Hasegawa, H., and Chatterjee, A. K. 2007. PsrA, the Pseudomonas sigma regulator, controls regulators of epiphytic fitness, quorum-sensing signals, and plant interactions in Pseudomonas syringae pv. tomato strain DC3000. Appl. Environ. Microbiol. 73:3684-3694.

Collmer, A., Badel, J. L., Charkowski, A. O., Deng, W. L., Fouts, D. E., Ramos, A. R., Rehm, A. H., Anderson, D. M., Schneewind, O., van Dijk, K., and Alfano, J. R. 2000. Pseudomonas syringae Hrp type III secretion system and effector proteins. Proc. Natl. Acad. Sci. U.S.A. 97:8770-8777.

Durand, J. M. B., Bjork, G. R., Kuwae, A., Yoshikawa, M., and Sasakawa, C. 1997. The modified nucleoside 2-methylthio-N6-isopentenyladenosine in tRNA of Shigella flexneri is required for expression of virulence genes. J. Bacteriol. 179:5777-5782.

Ferreira, A. O. , Myers, C. R., Gordon, J. S., Martin, G. B., Vencato, M., Collmer, A., Wehling, M. D., Alfano, J. R., Moreno-Hagelsieb, G., Lamboy, W. F., DeClerck, G., Schneider, D. J., and Cartinhour, S. W. 2006. Whole-genome expression profiling defines the HrpL regulon of Pseudomonas syringae pv. tomato DC3000, allows de novo reconstruction of the Hrp cis clement, and identifies novel coregulated genes. Mol. Plant-Microbe Interact. 19:1167-1179.

Fouts, D. E., Abramovitch, R. B., Alfano, J. R., Baldo, A. M., Buell, C. R., Cartinhour, S., Chatterjee, A. K., D’Ascenzo, M., Gwinn, M. L., Lazarowitz, S. G., Lin, N. C., Martin, G. B., Rehm, A. H., Schneider, D. J., van Dijk, K., Tang X., and Collmer, A. 2002. Genomewide identification of Pseudomonas syringae pv. tomato DC3000 promoters controlled by the HrpL alternative sigma factor. Proc. Natl. Acad. Sci. U.S.A. 99:2275-2280. 
Galan, J. E., and Collmer, A. 1999. Type III secretion machines: Bacterial devices for protein delivery into host cells. Science 284:1322-1328.

Grimm, C., Aufsatz, W., and Panopoulos, N. J. 1995. The hrpRS locus of Pseudomonas syringae pv. phaseolicola constitutes a complex regulatory unit. Mol. Microbiol. 15:155-165.

Hancock, R. E., and Brinkman, F. S. 2002. Function of Pseudomonas porins in uptake and efflux. Annu. Rev. Microbiol. 56:17-38.

Hendrickson, E. L., Guevera, P., and Ausubel. F. M. 2000. The alternative sigma factor RpoN is required for hrp activity in Pseudomonas syringae pv. maculicola and acts at the level of hrpL transcription. J. Bacteriol. 182:3508-3516.

Hutcheson, S. W., Bretz, J., Sussan, T., Jin, S., and Pak, K. 2001. Enhancer-binding proteins HrpR and HrpS interact to regulate hrp-encoded Type III protein secretion in Pseudomonas syringae strains. J. Bacteriol. 183:5589-5598.

Huynh, T. V., Dahlbeck, D., and Staskawicz, B. J. 1989. Bacterial blight of soybean: Regulation of a pathogen gene determining host cultivar specificity. Science 245:1374-1377.

Jacobs, M. A., Alwood, A., Thaipisuttikul, I., Spencer, D., Haugen, E., Ernst, S., Will, O., Kaul, R., Raymond, C., Levy, R., Chun-Rong, L., Guenthner, D., Bovee, D., Olson, M. V., and Manoil, C. 2003. Comprehensive transposon mutant library of Pseudomonas aeruginosa. Proc. Natl. Acad. Sci. U.S.A. 100:14339-14344.

Jin, Q., Thilmony, R., Zwiesler-Vollick, J., and He, S. Y. 2003. Type III protein secretion in Pseudomonas syringae. Microbes Infect. 5:301310

Joardar, V., Lindeberg, M., Jackson, R. W., Selengut, J., Dodson, R., Brinkac, L. M., Daugherty, S. C., Deboy, R., Durkin, A. S., Giglio, M. G., Madupu, R., Nelson, W. C., Rosovitz, M. J., Sullivan, S., Crabtree, J., Creasy, T., Davidsen, T., Haft, D. H., Zafar, N., Zhou, L., Halpin, R., Holley, T., Khouri, H., Feldblyum, T., White, O., Fraser, C. M., Chatterjee, A. K., Cartinhour, S., Schneider, D. J., Mansfield, J., Collmer, A., and Buell, C. R. 2005. Whole-genome sequence analysis of Pseudomonas syringae pv. phaseolicola 1448A reveals divergence among pathovars in genes involved in virulence and transposition. J. Bacteriol. 187:6488-6498.

King, E. O., Ward, M. K., and Raney, D. E. 1954. Two simple media for the demonstration of pyocyanin and fluorescein. J. Lab Med. 22:301307

Labes, M., Puhler, A., and Simon, R. 1990. A new family of RSF1010derived expression and lac-fusion broad-host-range vectors for gramnegative bacteria. Gene 89:37-46.

Lan, L., Deng, X., Zhou, J., and Tang, X. 2006. Genome-wide gene expression analysis of Pseudomonas syringae pv. tomato DC3000 reveals overlapping and distinct pathways regulated by $h r p L$ and $h r p R S$. Mol. Plant-Microbe Interact. 19:976-987.

Lan, L., Deng, X., Zhou, J. M., and Tang, X. 2007. Mutation of Lon protease differentially affects the expression of Pseudomonas syringae type III secretion system genes in rich and minimal media and reduces pathogenicity. Mol. Plant-Microbe Interact. 20:682-696.

Leung, H. C., Chen, Y., and Winkler, M. E. 1997. Regulation of substrate recognition by the MiaA tRNA prenyltransferase modification enzyme of Escherichia coli K-12. J. Biol. Chem. 272:13073-13083.

Preston, G., Deng, W. L., Huang, H. C., and Collmer, A. 1998. Negative regulation of hrp genes in Pseudomonas syringae by HrpV. J. Bacteriol. 180:4532-4537.

Quinones, B., Pujol, C. J., and Lindow, S. E. 2004. Regulation of AHL production and its contribution to epiphytic fitness in Pseudomonas syringae. Mol. Plant-Microbe Interact. 17:521-531.

Quinones, B., Dulla., G., and Lindow, S. E. 2005. Quorum sensing regulates exopolysacchride production, motility, and virulence in Pseudomonas syringae. Mol. Plant-Microbe Interact. 18:682-693.

Rahme, L. G., Mindrinos, M. N., and Panopoulos, N. J. 1992. Plant and environmental sensory signals control the expression of hrp genes in
Pseudomonas syringae pv. phaseolicola. J. Bacteriol. 74:3499-3507.

Rico, A., and Preston, G. M. 2008. Pseudomonas syringae pv. tomato DC3000 uses constitutive and apoplast-induced nutrient assimilation pathways to catabolize nutrients that are abundant in the tomato apoplast. Mol. Plant-Microbe Interact. 21:269-282.

Ritte, G., Rosenfeld, J., Rohrig, K., and Raschke, K. 1999. Rates of sugar uptake by guard cell protoplasts of Pisum sativum L. related to the solute requirement for stomatal opening. Plant Physiol. 121:647-656.

Salmeron, J. M., and Staskawicz, B. J., 1993. Molecular characterization and hrp dependence of the avirulence gene avrPto from Pseudomonas syringae pv. tomato. Mol. Gen. Genet. 239:6-16.

Shan, L., Thara, V. K., Martin, G. B., Zhou, J. M., and Tang, X. 2000. The Pseudomonas AvrPto protein is differentially recognized by tomato and tobacco and is localized to the plant plasma membrane. Plant Cell 12:2323-2338.

Sreedharan, A., Penaloza-Vazquez, A., Kunkel, B. N., and Bender, C. L. 2006. CorR regulates multiple components of virulence in Pseudomonas syringae pv. tomato DC3000. Mol. Plant-Microbe Interact. 19:768779.

Solomon, P. S., and Oliver, R. P. 2002. Evidence that gamma-aminobutyric acid is a major nitrogen source during Cladosporium fulvum infection of tomato. Planta 214:414-420.

Tanaka, R., and Tanaka, A. 2007. Tetrapyrrole biosynthesis in higher plants. Annu. Rev. Plant Biol. 58:321-346.

Tang, X., Xie, M., Kim, Y. J., Zhou, J., Klessig, D. F., and Martin, G. B. 1999. Overexpression of Pto activates defense responses and confers broad resistance. Plant Cell 11:15-29.

Tang, X., Xiao, Y., and Zhou, J. M. 2006. Regulation of the type III secretion system in phytopathogenic bacteria. Mol. Plant-Microbe Interact. 19:1159-1166.

Thwaites, R., Spanu, P. D., Panopoulos, N. J., Stevens, C., and Mansfield, J. W. 2004. Transcriptional regulation of components of the type III secretion system and effectors in Pseudomonas syringae pv. phaseolicola. Mol. Plant-Microbe Interact. 17:1250-1258.

Von Bodman, S. B., Bauer, W. D., and Coplin, D. L. 2003. Quorum sensing in plant-pathogenic bacteria. Annu. Rev. Phytopathol. 41:455-482.

Wei, C. F., Deng, W. L., and Huang, H. C. 2005. A chaperone-like HrpG protein acts as a suppressor of $\mathrm{HrpV}$ in regulation of the Pseudomonas syringae pv. syringae type III secretion system. Mol. Microbiol. 57:520-536.

Wei, W., Plovanich-Jones, A., Deng, W. L., Jin, Q. L., Collmer, A., Huang, H. C., and He, S. Y. 2000. The gene coding for the Hrp pilus structural protein is required for type III secretion of Hrp and Avr proteins in Pseudomonas syringae pv. tomato. Proc. Natl. Acad. Sci. U.S.A. 97:2247-2252.

Xiao, F., Goodwin, S. M, Xiao, Y., Sun, Z., Baker, D., Tang, X., Jenks, M. A., and Zhou, J. M. 2004. Arabidopsis CYP86A2 represses Pseudomonas syringae type III genes and is required for cuticle development. EMBO (Eur. Mol. Biol. Organ.) J. 23:2903-2913.

Xiao, Y., and Hutcheson S. W. 1994. A single promoter sequence recognized by a newly identified alternate sigma factor directs expression of pathogenicity and host range determinants in Pseudomonas syringae. J. Bacteriol. 176:3089-3091.

Xiao, Y., Heu, S., Yi, J., Lu, Y., and Hutcheson, S. W. 1994. Identification of a putative alternate sigma factor and characterization of a multicomponent regulatory cascade controlling the expression of Pseudomonas syringae pv. syringae Pss61 hrp and hrmA genes. J. Bacteriol. 176:1025-1036.

Xiao, Y., Lan, L., Yin, C., Deng, X., Baker, D., Zhou, J. M., and Tang, X. 2007. Two-component sensor RhpS promotes induction of Pseudomonas syringae type III secretion system by repressing negative regulator RhpR. Mol. Plant-Microbe Interact. 20:223-234.

Zhou, J. M., and Chai, J. 2008. Plant pathogenic bacterial type III effectors subdue host responses. Curr. Opin. Microbiol. 11:179-185. 